\title{
La «Economía Social y Solidaria» entre la restauración neoliberal y los gobiernos progresistas. Análisis de las políticas públicas implementadas en Argentina y México en el siglo XXI
}

\author{
The "Social and Solidarity Economy" between the neoliberal \\ restoration and progressive governments. Analysis of the public policies \\ implemented in Argentina and Mexico in the 21st century \\ Sofía Magali Vitali Bernardi*1, Leila Oulhaj ${ }^{2}$ \\ ${ }^{1}$ Becaria posdoctoral del ISHIR-CONICET (Rosario, Argentina) \\ 2 Doctora en Estudios Latinoamericanos por la UNAM
}

\begin{abstract}
Resumen: El sector de la Economía Social, Solidaria y/o Popular cobró actualmente una importante revitalización y relevancia tanto al interior de las investigaciones académicas y de las agendas estatales, como en la retórica de gran parte de las organizaciones sociales y políticas. Esto se debe al ascenso y visibilidad que adquirieron las heterogéneas prácticas populares vinculadas a la conformación de "otra economía», alternativa al neoliberalismo y la globalización, y a "nuevas» formas de organización y protesta social. Estas experiencias ganaron la escena pública y gravitaron en el diseño e implementación de políticas públicas orientada a la promoción de la "economía social y solidaria» a escala Latinoamericana.

En un escenario regional signado por la oscilación de gobiernos denominados "progresistas" y restauraciones neoliberales se vuelve central el análisis de diferentes aspectos del contexto histórico y sus implicancias en la formulación de los diferentes programas desarrollados y sus limitaciones en relación a las modalidades de implementación y trabajo propuestas para el sector en Argentina y México.
\end{abstract}

Palabras clave: Economía Social y Solidaria; Políticas Públicas; Gobiernos Progresistas; Neoliberalismo.

\begin{abstract}
The sector of the "Social, Solidarity and/or Popular Economy» currently received an important revitalization and relevance both within academic research and state agendas, as well as in the rhetoric of a large part of social and political organizations. This is due to the rise and visibility acquired by the heterogeneous popular practices linked to the formation of "another economy", an alternative to neoliberalism and globalization, and to «new» forms of organization and social protest. These experiences gained the public scene and gravitated in the design and implementation of public policies aimed at promoting the "social and solidarity economy" on a Latin American scale.

In a regional scenario marked by the oscillation of governments called "progressive" and neoliberal restorations, the analysis of different aspects of the historical context and its implications in the formulation of the different programs developed and their limitations in relation to the modalities of implementation and work proposals for the sector in Argentina and Mexico.
\end{abstract}

Keywords: Social and Solidarity Economy; Public politics; Progressive Governments; Neoliberalism.

Descriptores alfanuméricos: Z18 Public Policy; B55 Social Economics; R58 Regional Development Planning and Policy

* Correspondencia a/Corresponding author: Sofía Magali Vitali Bernardi. ISHIR-CONICET (Rosario, Argentina) sofiamvitali@gmail.com - https://orcid.org/0000-001-6179-9336

Cómo citar/How to cite: Vitali Bernardi, Sofía Magali; Oulhaj, Leila (2021). "La "Economía Social y Solidaria" entre la restauración neoliberal y los gobiernos progresistas. Análisis de las políticas públicas implementadas en Argentina y México en el siglo XX|», GIZAEKOA - Revista Vasca de Economía Social, 18, 37-74. (https://doi.org/10.1387/gizaekoa.22495).

Recibido: 25/01/2021; aceptado: 08/03/2021.

ISSN 1698-7446 - elSSN 2444-3107 / (c) 2021 UPV/EHU

cc) (i) Esta obra está bajo una licencia

Creative Commons Atribución 4.0 Internacional 


\section{Introducción}

El inicio del nuevo milenio en América Latina despuntó con altos niveles de descontento y conflictividad social protagonizado por movimientos de trabajadores y campesinos que cuestionaban la implementación de políticas neoliberales y gravitaron en el ascenso de una ola de gobiernos denominados "progresistas». Entre sus expresiones más significativas podemos mencionar las victorias electorales del Partido de los Trabajadores (PT) en Brasil, el Frente para la Victoria (FPV) en Argentina, el Frente Amplio (FA) en Uruguay, la Alianza País en Ecuador y el Movimiento al Socialismo (MAS) en Bolivia. En lo que respecta al caso Mexicano, más allá de la importancia de las movilizaciones y descontento popular, hubo una continuidad de gobiernos neoliberales, que recién se vieron impugnados discursivamente bajo el arribo al poder del partido Movimiento Regeneración Nacional (MORENA) de López Obrador en 2018.

Las condiciones de posibilidad que hicieron posible la emergencia del progresismo a escala regional se vinculan con el agotamiento de las políticas neoliberales debido a su fracaso en el objetivo de superar la crisis del capital financiero internacional, la crisis de legitimidad política de los partidos tradicionales y, como decíamos anteriormente, el escenario del ascenso de la lucha y conflictividad social (Moreira, 2017). Estos aspectos se vieron combinados con un período de bonanza económica ${ }^{1}$ que posibilitaron la implementación de proyectos de redistribución de la riqueza reduciendo los índices de pobreza y desigualdad.

En este contexto favorable, se destaca una reorientación de las políticas sociales desarrolladas por diferentes gobiernos Latinoamericanos que plantearon la ampliación del gasto social y el diseño de políticas multisectoriales mediante acciones públicas que involucraron a un gran número de destinatarios, impactando positivamente en una situación social apremiante (Caruana y Srnec, 2014). Bajo esta reorientación, se dieron diferentes avances relacionados a la Economía Social y Solidaria (ESyS) en la región vinculadas con procesos de implementación de nuevos programas y políticas públicas de sentido popular y avances en la formalización e institucionalización de la ESyS, mediante nuevos marcos legales, ya sea recono-

1 A partir de los ańos 2000 hasta 2015 la América Latina fue beneficiaria de un importante boom de altos precios de petróleo, cobre, oro, materias primas, productos agrícolas. Esto se expresó en importantes índices de crecimiento económico que ocurrió en casi todos los países, incluidos aquellos gobernados por los partidos burgueses tradicionales como México, Colombia, Chile, Perú, Costa Rica y, por supuesto en los «gobiernos progresistas» (Modonessi , 2015). 
ciendo sus formas propias, definiendo nuevas responsabilidades del Estado o modificando los marcos constitucionales (Coraggio, 2013; Caruana, 2016; Guerra, 2012).

Ahora bien, a menos de una década del surgimiento de los denominados gobiernos progresistas comenzaron a dar señales de agotamiento y regresión de sus proyectos. Esto será denominado por diferentes analistas como «fin del ciclo» progresista y su giro a la derecha; o cómo lo ha mencionado Modonessi (2015, p. 23), «el cierre de la etapa hegemónica de este ciclo». En tal sentido, si nos detenemos en el mapa político de América Latina, se registra que desde 2013 diferentes personajes encumbrados del neoliberalismo asumirán la presidencia de diferentes países de la región. Tales son los casos de los empresarios: Horacio Cartes (Paraguay); Juan Carlos Varela (Panamá); Mauricio Macri (Argentina); Jair Bolsonaro (Brasil), entre otros.

En lo relativo a la actividad económica se observa que en el año 2014, se produce un descenso de los precios del petróleo y de las materias primas, lo que repercutió en una importante desaceleración económica en la región ${ }^{2}$. Al deterioro de las economías, se suma el aumento del déficit público, la disparada de la inflación, y, por consiguiente, el estancamiento progresivo de la reducción de la pobreza y de la desigualdad ${ }^{3}$. Por otro lado, no resulta menor el impacto generado por la crisis sanitaria generada por la pandemia del Covid-19 para la región latinoamericana. Según estimaciones de la Cepal se prevé que la pandemia del Covid-19 sea la "causa de la mayor crisis económica y social de la región en décadas, con efectos

2 Para 2019, en México la tasa de crecimiento fue de 0,1\% y para 2020 la Comisión Económica para América Latina y el Caribe (Cepal) preveía antes de pandemia que se elevaría a $1,3 \%$. En cuanto a Argentina, en 2019, esta tasa fue de $0,21 \%$ (Statista, 2020) y para 2020 se esperaba que fuera de $0,24 \%$ (Statista, 2020).

${ }^{3}$ Los indicadores de pobreza y extrema pobreza muestran que en Argentina, la pobreza pasó de 40,5\% en octubre de 2000 a 65,5\% en mayo de 2003 (su nivel máximo) a 27,9\% en enero de 2018 (Gasparini, Tornarolli y Gluzmann, 2019: 21). Al primer semestre de 2019, $35,4 \%$ de la población vive bajo la línea de pobreza. En cuanto al porcentaje de personas viviendo en situación de indigencia, se elevaba a 9,9\% en octubre de 2000, para llegar a 27,2\% en mayo de 2003 y a 5,4\% en enero de 2018 (Gasparini et al., 2019: 24). A junio de 2019, aumentó a 7,7\% (Instituto Nacional de Estadística y Censos).

En México, el número muy alto de personas que viven en condiciones de pobreza y extrema pobreza permiten de igual forma subrayar la exclusión de la mayor parte de la población del programa hegemónico. Según las cifras del Consejo Nacional de Evaluación de la Política de Desarrollo Social (Coneval), entre 2008 y 2018, el porcentaje de la población que vive en condición de pobreza pasó de $44,4 \%$ a $41,9 \%$. En cuanto a la población que vive en extrema pobreza, el porcentaje disminuyó de 11 a 7,4\%. 
muy negativos en el empleo, el combate a la pobreza y la disminución de la desigualdad» (CEPAL, 2020) $)^{4}$.

Considerando este contexto sociohistórico y político general, en el siguiente artículo nos proponemos analizar la aparición, formulación e implementación de las políticas vinculadas a la ESS en México y Argentina. Nuestro abordaje focalizará en diferentes aspectos del contexto histórico particulares de ambos países para entender la emergencia de éstas políticas públicas. Asimismo, tomaremos en consideración las principales características de los diferentes programas desarrollados y sus limitaciones en relación a las modalidades de implementación y trabajo propuestas.

En términos teórico-metodológicos, partimos de entender a la Economía Social y Solidaria como concepto amplio que abarca tanto a las experiencias conformadas por organizaciones con institucionalidad jurídica como cooperativas, mutuales y asociaciones que tradicionalmente se incluyeron bajo la Economía Social, como también a las diferentes experiencias económicas más recientes de los sectores subalternos tales como las cooperativas de trabajadores, fábricas recuperadas, redes de trueque y emprendimientos productivos denominadas bajo el concepto de Economías Solidarias (Pérez de Mendiguren y Etxezarreta, 2015).

De esta manera, la Economía Social y Solidaria se erige como una categoría que engloba una serie de prácticas heterogéneas que son concebidas como subsistema de la economía que a diferencia de la economía empresarial capitalista y de la economía pública, se orienta hacia la reproducción ampliada de la vida y no por la acumulación de capital. Asimismo, es pensada como propuesta transicional que orienta prácticas transformadoras desde la economía mixta existente hacia otro sistema socioeconómico con una racionalidad diferente (Coraggio, 2007; Hintze, 2007).

En lo que respecta a las políticas sociales entendemos que son parte constitutiva y expresión del régimen de reproducción —en tanto conjunto de intervenciones sociales del Estado- que se articula con un determinado ordenamiento económico y político. Es decir, son la forma política de la cuestión social, la cual se expresa y materializa en las políticas sectoriales, incluyendo la política laboral, delimitando los alcances de la mercantilización de la fuerza de trabajo (Grassi, 2003). De este modo, el conjunto de intervenciones y regulaciones de las mismas pone de manifiesto la consideración que adquiere el trabajo humano en la producción y, en consecuen-

${ }^{4}$ Con la pandemia del Covid-19, la Cepal revisó su cifra y pronostica que sea de $-6,5 \%$. Para México, en 2019, se registró una tasa negativa de 0,3\% de crecimiento del PIB y para 2020 el Fondo Monetario Internacional (FMI) estimaba a un crecimiento de 1\%. La pandemia relacionada con el coronavirus llevó a la Cepal a pronósticos de decrecimiento del orden del $6,5 \%$ para 2020. 
cia, la consideración que merece el sujeto del trabajo, que son ambos la razón de ser de las políticas de empleo, salariales, de asistencia al desempleo, de seguridad y protección social (Grassi, 2012). En cada momento histórico, la definición de la cuestión social pone de manifiesto el consenso social acerca de qué problemas se constituyen como tales, los cuales son expresión de la lucha de clases y grupos sociales por imponer el reconocimiento de sus derechos y la satisfacción de sus necesidades (Raggio, 2005).

Desde estas coordenadas, entendemos que la aparición de las categorías de Economía Social y Solidaria al interior de la agenda estatal en la región, se configura como resultado de un proceso complejo en el que gravitan tanto la creciente conflictividad social encabezada por los movimientos sociales comprometidos con propuestas económicas alternativas vinculadas a la ESyS; como también el aumento del excedente de mano de obra urbana y calificada, consecuencia de la crisis de la sociedad salarial, el crecimiento del desempleo y la pobreza, generados a partir de la última reestructuración capitalista (Palomino, 2004; Caruana, 2016).

De esta manera, aunque con diferentes énfasis y visiones sobre el significado y alcance de la ESyS, las diferentes iniciativas estatales han incorporados elementos de estas experiencias económicas como respuesta a las demandas de estos sectores organizados; como también como mecanismos de inclusión social de la población empobrecida que no puede ser incorporada al mercado de trabajo. Esta característica general se torna explicativa de su persistencia tanto bajo regímenes de gobierno progresistas como también neoliberales de la región. Asimismo, esto vuelve relevante analizar sus avances y limitaciones presentes para la consolidación de formas de trabajo más humanas y solidarias para la reproducción digna de la vida.

Metodológicamente, recurrimos al análisis de diversas fuentes de información, entre ellas documentos oficiales (normativas, resoluciones ministeriales, decretos y leyes de regulación y promoción del trabajo asociativo, cooperativo y autogestionado), sitios web institucionales e información de prensa. Asimismo, recuperamos aportes de investigaciones de corte cualitativo sobre estas políticas.

En términos expositivos, presentaremos en primer lugar al caso argentino en dos apartados: uno dedicado al surgimiento de las políticas de «Economía Social y Solidaria» bajo los gobiernos kirchneristas (20032015) y un segundo apartado con las transformaciones recientes, generadas a partir de la asunción de la Alianza Cambiemos (2015-2019). Posteriormente seguiremos con el caso Mexicano, donde describiremos en primer lugar los primeros dispositivos estatales generados para la «Economía Social y Solidaria» bajo lo que denominamos "gobiernos neoliberales abiertos» desarrollados por el Partido Acción Nacional (PAN) durante 20062012 y el Partido Revolucionario Institucional (PRI) entre 2012-2018 y; 
subsiguientemente las transformaciones generadas durante el gobierno de Movimiento Regeneración Nacional (MORENA) desde 2018 en adelante. Finalmente expondremos las reflexiones finales destacando las particularidades de cada caso.

\section{El caso Argentino: entre el surgimiento desde abajo de políticas de «Economía Social y Solidaria» y la normalización del conflicto social en el período postconvertibilidad ${ }^{5}$}

Las políticas orientadas a la ESyS en Argentina emergen a partir de la crisis del año 2001 y se consolidan durante la gestión de gobierno del 2003 , en un contexto de gran visibilidad y conflictividad social que protagonizaron numerosos tipos de organizaciones, movimientos sociales, centros comunitarios, cuya expresión más masiva y consolidada fueron los distintos agrupamientos de trabajadores desocupados y las denominadas Empresas Recuperadas (ER) ${ }^{6}$ (Manzano, 2013; Ciolli, 2013). Estos agrupamientos impugnaban al Estado por la creación y/o mantenimiento de puestos de trabajo; ayuda social para los hogares de desocupados (alimentos, medicinas, etc.); y más tardíamente por el aumento de vacantes en los programas de empleo transitorio (Fernández Álvarez y Manzano, 2007).

Durante el gobierno de Néstor Kirchner, quien asume la presidencia en el año 2003, comienza un proceso de reconstrucción del poder y legitimación del Estado y de normalización del conflicto social, proceso que se desarrolló sobre la base de la incorporación de demandas de los sectores movilizados. Especialmente significativo fue el giro en materia de política

5 Las transformaciones que se generaron a partir de 2003 en Argentina, están atravesadas por el período iniciado durante la denominada postconvertibilidad, a partir de la cual se generaron ciertos contrastes con respecto al desenvolvimiento económico, social y político que caracterizó a los años noventa. Dichos contrastes se desplegaron tanto en lo que respecta a la recomposición de la acumulación capitalista como en la dominación social, posterior al estallido de la crisis en el ańo 2001 (Marticorena, 2014). Entre las acciones desarrolladas por el Estado se resalta un conjunto decisiones económicas sobre el modelo de crecimiento, el aumento de su capacidad regulatoria en la inspección del trabajo y el fortalecimiento de la negociación colectiva (Salvia, 2010).

${ }^{6}$ El término Empresas Recuperadas (ER) fue acuñado para definir aquellas empresas en crisis o en proceso de quiebra, en las que sus trabajadores se proponen continuar con la actividad productiva a los fines de mantener la fuente de trabajo. Algunas de estas experiencias surgieron en Argentina desde mediados de la década de los 90 y adquirieron mayor gravitación a partir de la crisis de fines de los 2000 (Deux Marzi, 2007). En nuestro país, según el informe realizado por Ruggeri (2014), existen 311 empresas recuperadas que ocupan alrededor de 13.462 trabajadores. 
social hacia las organizaciones de desocupados y sus reclamos (Piva, 2013). Es importante destacar que este viraje se inscribe en un contexto de recuperación económica que sin embargo no logra revertir el deterioro estructural generado por los efectos de la aplicación de medidas de corte neoliberal durante los '90. Entre estos se destacan, los elevados niveles de desempleo, informalidad y precariedad laboral, como también de altos índices de conflictividad social, que tenían como protagonistas principales a trabajadores desocupados y del sector informal.

En este contexto general, las políticas sociales de ESyS fueron presentadas desde los discursos de funcionarios y agentes estatales como parte del denominado "giro productivista" y en oposición a las políticas asistenciales y focalizadas propias de la década anterior. Las mismas se propusieron como un cambio de paradigma con el objetivo de "cortar con el asistencialismo» y generar «fuentes de trabajo» a partir de otras formas productivas (cooperativas y emprendimientos productivos). En esta oposición, se recuperó la noción de «trabajo genuino» en contraposición a la «asistencia» entendida como límite para el incentivo de la «cultura del trabajo» y como componente de políticas focalizadas que favorecerían prácticas de "clientelismo político» (Fernández Álvarez y Manzano, 2007).

En acuerdo con Vanesa Ciolli (2013), consideramos que las políticas de ESyS en Argentina configuran un tipo específico de intervenciones estatales no convencionales en el mercado de trabajo, que tornan muy difusas las fronteras entre políticas de asistencia y políticas laborales. De esta manera, el Estado asume un papel particular en el mercado laboral a través del diseño de dispositivos gubernamentales orientados a estimular el autoempleo en ciertos sectores de la población económicamente activa desempleada, incentivando especialmente proyectos asociativos. Tales medidas fueron acompañadas por repercusiones a nivel simbólico e institucional, ya que se alteraron un conjunto de dinámicas estatales en el área social.

A partir de esta caracterización general, nos interesa presentar brevemente las principales áreas estatales, planes y programas nacionales desde los cuales se recuperan los lineamientos y propuestas de la denominada ESyS. Particularmente, nos referiremos a las desarrolladas por los Ministerio de Desarrollo Social (MDS) y el Ministerio de Trabajo, Empleo y Seguridad Social (MTEySS) ya que fueron los ámbitos institucionales más importantes y activos en términos de sus alcances y desarrollos.

Dentro de la órbita del Ministerio de Desarrollo Social de la Nación, se cuenta con la existencia del INAES (Instituto Nacional de Asociativismo y Economía Social), cuya creación data del año 2000. Este instituto es la autoridad de aplicación del régimen legal cooperativo y mutual que tiene bajo su órbita facultades y atribuciones institucionales-corporativas exclusivas e intransferibles en materia de cooperativas y mutuales en todo el país, 
siendo su fin principal la promoción, desarrollo, fiscalización y sanción de las mismas.

Bajo este organismo una de las principales acciones fue la modificación a la Ley de Quiebras (N.o 24552) en el año $2002^{7}$, la cual tendió hacia la legalización de la situación de los trabajadores de Empresas Recuperadas (ER). Entre las principales transformaciones se incluyeron: el formato de "cooperativa de trabajo» para la recuperación del establecimiento, el reconocimiento de sus trabajadores ya no como «usurpadores» y un mayor margen para los jueces en el manejo de los plazos en que pueden permanecer en la empresa (período de continuidad).

En el año 2011 se promulga una nueva Ley de Quiebras, la 26.684 donde se intenta contemplar los intereses de los trabajadores de ER. Entre sus disposiciones se habilita la participación activa de sus trabajadores en la quiebra; se regulariza la situación de las cooperativas de trabajadores que administran estas empresas de modo de posibilitar su adquisición aun cuando la cooperativa esté en formación; también se les otorga prioridad de adquisición de una empresa cerrada, regularizando aquellas cooperativas que se encuentran en esa situación; por último, se facilita la explotación de cooperativas tomando como herramienta de pago todos los créditos laborales al momento de la quiebra, incluida la indemnización, salarios caídos y otras remuneraciones y derechos no abonados (Valentino, Solero y Lagiu, 2011).

Otro avance legislativo se produce en el 2006 cuando se sanciona la Ley 26.117 de Promoción del Microcrédito para el desarrollo de la Economía Social, gestionado por la Comisión Nacional de Microcrédito (CONAMI). Esta última, impulsa el acceso a microcréditos destinados a trabajadores, trabajadoras mayores de 18 años y/o grupos asociativos de la economía popular y solidaria que necesitan financiamiento para sus actividades. Estos préstamos pueden utilizarse para compra de insumos, materiales y herramientas en emprendimientos productivos, de servicios o comerciales.

Además de los progresos legales, el INAES cuenta con un área específica para atender a las ER, específicamente en lo que respecta a: asistencia técnica a los grupos cooperativos de trabajadores de empresas/fábricas en crisis y, apoyo financiero con recursos específicos del fondo de promoción y educación cooperativa (Fontenla, 2007).

7 Como se plasma en la modificación del artículo 190 de la ley 24.552 que queda redactado de la siguiente manera: "Artículo 190: En toda quiebra, aun las comprendidas en el artículo precedente, el síndico debe informar al juez dentro de los veinte (20) días corridos contados a partir de la aceptación del cargo, sobre la posibilidad excepcional de continuar con la explotación de la empresa del fallido o de alguno de sus establecimientos y la conveniencia de enajenarlos en marcha» (Ley de Quiebras N.o 24552/02). 
A continuación, nos interesa detenernos en los diferentes programas nacionales implicados en la promoción de la denominada ESyS creados por el Ministerio de Desarrollo Social (MDS) y el Ministerio de Trabajo, Empleo y Seguridad Social (MTEySS). En tal sentido, fueron identificadas algunas de sus tendencias en relación a los destinatarios de las mismas y objetivos propuestos. Posteriormente, debatiremos sobre las diferentes modalidades de trabajo propuestas y sus principales dificultades.

Al interior del MDS, se destaca la aparición —en el año 2004- del denominado Plan de Desarrollo Local y Economía Social «Manos a la Obra» (en adelante PMO). El PMO, fue una política social con orientación socioproductiva que incentivó la generación de autoempleo. De este modo, se canalizó la creciente legitimidad social lograda por las iniciativas sociales asociativas - tales como cooperativas, microemprendimientos y empresas recuperadas - que organizaciones y grupos sociales venían desarrollando al calor de la crisis. Recuperando lo planteado por Malena Hopp (2009), el PMO estuvo destinado particularmente a los sectores de bajos recursos y se planteó tres objetivos principales: en primer lugar, contribuir a la mejora del ingreso de la población en situación de vulnerabilidad social en todo el país; promover, en segundo lugar, la "economía social» mediante el apoyo técnico y financiero a emprendimientos productivos de inclusión social generados en el marco de procesos de desarrollo local. Y finalmente, fortalecer a organizaciones públicas y privadas, así como a espacios asociativos y redes, a fin de mejorar los procesos de desarrollo local e incrementar el capital social, mejorar su efectividad y generar mayores capacidades y opciones a las personas, promoviendo la descentralización de los diversos actores sociales de cada localidad.

Como es destacado en las investigaciones de Vanesa Ciolli y Carla Rodríguez (2011), producto de la evidente falta de sustentabilidad de los emprendimientos financiados, en una segunda etapa del PMO se apeló a las organizaciones sociales territoriales para que garantizaran la sostenibilidad de los proyectos productivos. Las autoras subrayan que las organizaciones que participaron fueron mayoritariamente afines al gobierno, como $\mathrm{Ba}-$ rrios de Pie y Federación de Tierra y Vivienda (FTV), mientras que algunas tuvieron posiciones más críticas, entre las que se ubican el Movimiento Territorial de Liberación (MTL) y los Movimientos de Trabajadores Desocupados (MTD's). Esto se hizo particularmente evidente hacia el 2008, momento a partir del cual se reorientan los subsidios hacia componentes centrados en microcréditos individuales gestionados por las propias organizaciones sociales a través de comités multisectoriales.

Durante el ańo 2009, en el contexto de crisis financiera internacional, el Gobierno Nacional profundizó la propuesta de generación de trabajo asociativo desde la política social a través de la puesta en marcha del 
Programa de Ingreso Social con Trabajo "Argentina Trabaja» (PRIST-AT) (Hopp, 2013). Cabe destacar que este plan solo alcanzó a las provincias de Buenos Aires, Corrientes, Entre Ríos, Mendoza y Tucumán y todavía no se ha implementado en la provincia de Santa Fe. El propósito enunciado por el mismo fue la generación de «trabajo genuino», a través de la creación de cooperativas de trabajo, orientadas al mejoramiento de la infraestructura barrial y la calidad de vida de las familias vulnerables (MDS, 2010). Y los destinatarios "personas sin ingresos en el grupo familiar, ni prestaciones de pensiones, jubilaciones nacionales, ni planes del Ministerio de Trabajo, Empleo y Seguridad Social o provinciales» (MDS, 2010). En cuanto a su implementación, se observa que este Programa propuso la creación de cooperativas de trabajo, integradas por al menos sesenta personas, a fin de que las mismas realicen obras públicas vinculadas con labores de baja y mediana complejidad para el mejoramiento de la infraestructura y el hábitat barrial de las localidades más vulnerables del país. Asimismo, el Programa dispuso la capacitación en oficios, en organización cooperativa y en temáticas sociales, educativas, de salud y prevención para los cooperativistas. Para ello se brindó asistencia técnica y becas de capacitación (Hopp y Giménez, 2011).

Es importante destacar que para el año 2010 diversos programas de ESyS se unificaron como componentes de "Argentina Trabaja». Entre ellos se destacan: Proyectos Socio-productivos "Manos a la Obra»; Marca Colectiva; Microcréditos; el Programa Ingreso Social con Trabajo y finalmente, el Monotributo social (Hintze, 2018)

En el año 2013, se inaugura dentro del esquema PRIST-AT la línea «Ellas Hacen» destinado a 100,000 mujeres desocupadas con tres o más hijos/as a cargo, hijo/a discapacitado/a o en situación de violencia. Al igual que PRIST-AT, se promueve la organización de las destinatarias en cooperativas de trabajo, favoreciendo de esta forma el trabajo asociado y autogestivo, en línea con los postulados de la economía social. Desde una perspectiva de género, el diseño del programa no prevé una oferta de servicios de infraestructura de cuidado por parte del Estado. De esta manera, las actividades orientadas a promover la autonomía de las mujeres se ven tensionadas por las propias tareas reproductivas que realizan en sus hogares y por lo tanto contribuye a la sobrecarga de trabajo de las mujeres (Arcidiacono y Bermudez, 2018). Por otro lado, se registra que las actividades y oficios propuestos reproducen ciertos estereotipos de género vinculados a tareas y actividades femeninas, la mayoría de las cooperativas del Programa son textiles o gastronómicas, dos oficios generalmente femeninos.

Es importante destacar que las dos versiones del PRIST-AT representaron un fenómeno que fue denominado como el «boom del cooperativismo de trabajo bajo programas». Su envergadura se advierte al observar 
el aumento exponencial de cooperativas de trabajo en Argentina, las cuales pasaron de ser 955 en 2003, hasta llegar a 17,704 en 2015. Entre estas 2,897 pertenecen a la línea Ellas Hacen, en la cual participan alrededor de 92,420 mujeres (Nadur, 2019). En líneas generales, la incorporación del cooperativismo se produjo como una variante del empleo público precario y transitorio para la ejecución de trabajos de mejora de infraestructura pública (Ciolli y Rodríguez, 2011). Por otro lado, bajo este programa, las organizaciones sociales territoriales jugaron un papel central en la selección de los beneficiarios y en la gestión de los proyectos. En este sentido, como destacan diferentes investigaciones (Perelmiter, 2010; Abons y Pacifico, 2013), la incorporación de militantes y referentes de distintas organizaciones y movimientos sociales al trabajo de diseño, implementación y gestión de las políticas sociales fue parte del proceso de reorientación de políticas que comenzó en el 2003 y que se propuso como parte de una intervención más activa en el territorio.

En acuerdo con Malena Hopp (2009), consideramos que los distintos programas desarrollados al interior del Ministerio de Desarrollo Social apuntan a los sectores considerados inempleables que, desde los propios dispositivos estatales, son denominados como los más vulnerables en cuanto a su inserción laboral. De esta manera, se plantea como propósito promover la integración social de los sujetos a través de la generación de autoempleo. En este marco, el desarrollo de emprendimientos socioproductivos y cooperativas de trabajo aparece como la vía escogida para ello.

$\mathrm{Al}$ interior del MTEySS también se desarrollan diferentes programas orientados a la ESyS, el trabajo asociativo y el autoempleo. En el año 2004, a través del decreto 1506/04 se comenzó a promover el pasaje de los destinatarios del Plan Jefas y Jefes de Hogar Desocupados, que se encontraban bajo su órbita, hacia otros programas que favorecieran la creación de empleo genuino y la transformación de programas asistenciales en políticas de integración social y productiva de la población desocupada utilizando criterios de empleabilidad. De esta manera, los beneficiarios que permanecían bajo su salvaguardia fueron reubicados en dos conjuntos: tras la evaluación de su empleabilidad, una parte fue incorporada a los planes de capacitación y empleo de MTEySS; otra parte fue la que incluyó beneficiarios del Plan Nacional de Desarrollo Local y Economía Social «Manos a la Obra» o del Plan Familias por la Inclusión Social, gestionados por el MDS (Grassi, 2012). Al mismo tiempo, se dieron de baja a los destinatarios que habían conseguido un empleo y/o a los que dejaron de cumplir con los requisitos de acceso (Hopp, 2009). Así, comenzaron a implementarse diversos planes de autoempleo, entre ellos el Seguro de Capacitación y Empleo y el Plan de Promoción del Empleo. Dentro de este último, ubicamos al Programa «Herramientas por Trabajo» que se puso en marcha en el año 2005. Como 
fue documentado por Malena Hopp (2009), este programa estuvo dirigido a trabajadores desocupados beneficiarios del Programa Jefes de Hogar con el propósito de promover la inserción laboral de las personas desocupadas mediante el desarrollo de un proyecto productivo de carácter asociativo. En este mismo marco, se ejecutó el Programa Inserción Laboral (PIL)-autoempleo, destinado a trabajadores desocupados del Seguro de Capacitación y Empleo, el cual se propuso facilitar la inserción laboral a través de la realización de emprendimientos productivos individuales o asociativos. El programa apuntó a que el trabajador que quisiera desarrollar un oficio o concretar un proyecto de autoempleo pudiera recibir, anticipadamente y en un solo pago, el monto de las cuotas que le restaba por cobrar del Seguro de Capacitación y Empleo. El requisito para el financiamiento era la presentación y aprobación por parte del MTEySS de un proyecto de autoempleo. Al igual que "Herramientas por Trabajo», brindó asistencia técnica y capacitación para la formulación y desarrollo de proyectos productivos, contando además con tutorías durante el desarrollo del proyecto.

Por otro lado, dentro del MTEySS se generaron una serie de programas orientados principalmente a atender a los sectores de empresas recuperadas y, en menor medida, cooperativas de trabajo. En el año 2004 se creó el Programa de Trabajo Autogestionado (PTA), cuyo objetivo era "contribuir al mantenimiento y la generación de puestos de trabajo por medio de la promoción y fortalecimiento de empresas recuperadas por sus trabajadores, que se encuentren en funcionamiento o en proceso de reactivación» (Portal del MTEySS). Entre los componentes del PTA se ubica el Programa de Competitividad para Empresas Autogestionadas y Sistematización de Modelos de Gestión, generado en el 2006 con el fin de «contribuir a mejorar la competitividad y sustentabilidad de las Pequeñas Empresas Autogestionadas por los trabajadores y apoyar la aplicación de modelos de gestión empresarial sostenibles» (Portal del MTEySS). Desde el programa se brindó asistencia para promover la incorporación de políticas preventivas y correctivas en materia de mejoramiento de las condiciones de higiene y seguridad en el trabajo, la provisión de equipamiento básico y el reacondicionamiento del equipamiento existente.

Es importante destacar que, si bien incorporaron paulatinamente regímenes especiales que buscaron brindar previsión social, cobertura de salud a los trabajadores de este tipo de emprendimientos y asignaciones familiares, no se formularon mecanismos capaces de concebir a los integrantes de los emprendimientos como titulares efectivos de derechos (Ciolli, 2009).

A partir de lo desarrollado podemos plantear que el surgimiento y expansión de políticas sociales vinculadas a la ESyS durante los gobiernos Kirchneristas se produce en un contexto de alza de la conflictividad social de movimientos de trabajadores desocupados y experiencias de ER, como 
también de limitaciones del mercado de trabajo para incorporar la mano de obra excedente. Bajo esta coyuntura, los dispositivos estatales se orientaron a la creación de empleo e ingresos de la población en condiciones de exclusión, pero bajo grandes limitaciones de incidir de manera estructural en las condiciones socioeconómicas de las personas destinatarias. Por otro lado, se destaca el lugar central que adquirieron las organizaciones sociales y territoriales vinculadas a la ESyS en los procesos de implementación y gestión de estos programas, lo que representó un avance en su reconocimiento como interlocutores válidos y como antecedente para la formulación y puesta en práctica de procesos de coproducción de las políticas públicas. Sin embargo, resultaron escasos los avances tendientes a consolidar un subsector económico alternativo viéndose restringido como instrumento de inclusión social del período.

\subsection{Transformaciones recientes de la politica social: la restauración neoliberal $y$ sus implicancias en las políticas de ESyS}

En este apartado recorreremos ciertas transformaciones en materia de política social que se producen a partir del año 2015 hasta el 2019, considerando algunas de las repercusiones generadas a partir de la asunción del presidente Mauricio Macri y la gestión de la coalición política Alianza Cambiemos. Desde entonces se produce el ascenso de sectores de la derecha al poder político del país, con un relanzamiento de iniciativas neoliberales, que redundaron en una serie de modificaciones de la orientación política y económica del país y gravitaron en las políticas y actores de la ESyS.

Entre las principales transformaciones se incluyó una fuerte devaluación de la moneda, apertura económica, eliminación de retenciones a la exportación de productos agrícolas, quita de subsidios a servicios públicos, entre otras medidas. Esto incidió en un marcado incremento de costos de insumos y herramientas de trabajo, creciente inflación y la consiguiente pérdida de poder adquisitivo de los salarios, acompañado del aumento del desempleo.

En este contexto, las cooperativas de trabajo, empresas recuperadas y otras experiencias asociativas y autogestionadas se vieron particularmente afectadas en el sostenimiento de su producción. Según el informe de situación de las empresas recuperadas elaborado por el Programa Facultad Abierta, a fines del 2017 el 80\% experimentó bajas de producción y un $12 \%$ directamente estaba sin producir (sobre el relevamiento de 73 ER). Asimismo, el informe destaca una fuerte pérdida de puestos de trabajo, resultado del alejamiento de los trabajadores en búsqueda de mayores ingresos. Hasta diciembre del 2015 se registraba un panorama de expansión del número de empresas y trabajadores, en el 2017 se observa una disminución 
absoluta de 1,400 puestos de trabajo respecto del 2015 pese a la existencia de nuevas recuperaciones, unas 25 durante el gobierno de Mauricio Macri (Facultad de Filosofía y Letras UBA, 2017).

Fue entonces que las organizaciones que nucleaban a gran parte de estas experiencias protagonizaron importantes movilizaciones en el marco del lanzamiento de una campaña para exigir la sanción de la Ley de Emergencia Social (n. $\left.{ }^{\circ} 27345\right)$. Para esto fue muy importante el accionar conjunto de estas organizaciones mediante una alianza entre la Confederación de Trabajadores de la Economía Popular (CTEP) ${ }^{8}$ y las organizaciones sociales Barrios de $\mathrm{Pie}^{9}$ y la Corriente Clasista y Combativa $(\mathrm{CCC})^{10}$, los cuales son los sectores más representativos y numerosos de la Economía Popular en Argentina.

En diciembre de 2016, lograron que se sancione dicha ley, cuyo objetivo es la promoción y defensa de

los derechos de los trabajadores y trabajadoras que se desempeñan en la economia popular, en todo el territorio nacional, con miras a garantizarles alimentación adecuada, vivienda digna, educación, vestuario, cobertura médica, transporte y esparcimiento, vacaciones y protección previsional, con fundamento en las garantías otorgadas al trabajo en sus diversas formas (en la Constitución Nacional]. (Ley de Emergencia Social, n. ${ }^{0}$ 27345)

En el marco de esta legislación se crea bajo la órbita del Ministerio de Desarrollo Social de la Nación: el Consejo de la Economía Popular, el Registro Nacional de la Economía Popular y el Salario Social Complementa-

${ }^{8}$ En el año 2011 se conforma la Confederación de Trabajadores de la Economía Popular (CTEP) de la cual forman parte: el Movimiento Evita, MTE, el Movimiento Popular La Dignidad (MPLD), El Movimiento Nacional Campesino Indígena (MNCI), el Movimiento Nacional de Empresas Recuperadas, Los Pibes, Patria Grande, el Movimiento Pueblo Unido, la Seamos Libres, el Encuentro de Organizaciones, la OLP, la Unión de los Trabajadores de la Tierra, La Poderosa, los Misioneros de Francisco y la Carlos Mujica. El objetivo de este nucleamiento se promueve el reconocimiento de las actividades productivas que esta población realiza en tanto trabajo, reivindicando a la economía popular como una categoría identificatoria de este sector. Este reconocimiento articula la construcción de demandas orientadas a conquistar derechos asimilables a los de aquellos trabajadores que se encuentran en relación de dependencia. Asimismo desde este espacio gremial, plantean y proclaman la construcción de una «nueva economía» que rompa con la lógica de la ganancia, inherente al modo de acumulación capitalista (Vitali, Cavigliasso y Lilli, 2019).

9 El Movimiento Barrios de Pie se conformó a finales del 2001, impulsada por la Corriente Patria Libre, luego Libres del Sur. Es una organización que busca nuclear los reclamos de los trabajadores desocupados a nivel nacional.

${ }^{10}$ La Corriente Clasista y Combativa es una agrupación política y sindical argentina impulsada por el Partido Comunista Revolucionario que se formó en 1994. En el año 1996 dedicó particular atención a la organización de los trabajadores desocupados, transformándose en una de las más conocidas expresiones del movimiento piquetero del país. 
rio (CEPSSC). El Consejo ${ }^{11}$ será el encargado de construcción del Registro Nacional de la Economía Popular (RENATREP), en el cual se deberán inscribir los trabajadores para percibir dicho salario. También será el encargado de negociar los montos y números de beneficiarios y puede diseñar y proponer los criterios y mecanismos de inscripción, admisión, clasificación y permanencia en el Registro Nacional de la Economía Popular, formular propuestas y recomendaciones al poder ejecutivo (Muñoz, 2019).

Por su parte, el Salario Social Complementario se concibe como un complemento del trabajo en la economía popular y remite a una compensación individual destinada a aquellos trabajadores que se encuentran en una situación de informalidad y precariedad, percibiendo ingresos menores al Salario Mínimo Vital y Móvil ${ }^{12}$ y sin cobertura de la seguridad social. De esta manera, su objetivo es lograr cierta igualación o compensación de las situaciones de desigualdad generadas en el mercado de trabajo. Así, puede pensarse como un avance en tanto implica un cambio en la consideración del «beneficiario» como «trabajador» y del «ingreso» como «salario» que permite la construcción de regulaciones y protecciones sociales para este sector (Maldovan Bonelli et al., 2017). Ahora bien, cómo destaca Malena Hopp (2017), es importante destacar que esta nueva reglamentación implicó una progresiva transformación de muchos de los programas nacionales orientados a la economía social bajo el denominado Salario Social Complementario. Nos referimos a que la opción por una transferencia individual fundada en la emergencia pública fue en desmedro de la propuesta de creación de puestos de trabajo en cooperativas, es decir, en el marco de formas de organización colectiva de los trabajadores/as. De esta manera, la denominación de esta transferencia como salario borra nuevamente la asociatividad y la autogestión del trabajo que los programas implementados desde el año 2003 (Hopp, 2017).

A continuación queremos referirnos a las transformaciones de las principales líneas y programas orientados a la ESyS. En primer lugar, es importante mencionar que el gobierno de Cambiemos utilizó estas políticas públicas preexistentes — tanto del MTEySS como del MDS — para atenuar

11 Si bien el Consejo de la Economía Popular y Salario Social Complementario (CEPSSC) dependen del MDS, quienes están autorizados a participar de las negociaciones que se producen en ese Consejo son por parte del Estado son el Ministerio de Trabajo y Seguridad Social, el Ministerio de Desarrollo Social, el Ministerio de Hacienda y Finanzas Públicas y por parte de las organizaciones sociales: tres inscriptas en el Registro de Organizaciones Sociales de la Economía Popular y Empresas Auto gestionadas (Muñoz, 2019).

12 Según establece la Ley de Contrato de Trabajo, el salario mínimo vital y móvil se define como «la menor remuneración que debe percibir en efectivo el trabajador sin cargas de familia, en su jornada legal de trabajo, de modo que le asegure alimentación adecuada, vivienda digna, educación, vestuario, asistencia sanitaria, transporte y esparcimiento, vacaciones y previsión» (Ley 20744 Titulo IV CAPITULO II). 
el impacto de la recesión, la devaluación de la moneda y el aumento del desempleo y contener posibles conflictos sociales de los sectores populares. Asimismo, modificó de manera drástica las principales orientaciones y modalidades de implementación de estos programas.

Como documenta el investigador Juan Pablo Hudson (2019), al interior del MTEySS hubo un crecimiento presupuestario geométrico para el Programa de Trabajo Autogestionado (PTA), el cual tiene como principal beneficiario a las Empresas Recuperadas. Este presupuesto se dispuso como transferencia de subsidios para las Empresas que, cómo hemos señalado, habían ingresado en un período de crisis y demandaron ayuda financiera al Estado. Sin embargo, el criterio utilizado para su otorgamiento respondió a criterios empresariales, en desmedro de la economía social o la popular que anteriormente tenia. Particularmente, la estrategia consistió en diferenciar entre las ER y cooperativas que cuentan con capacidad de empleabilidad y comercialización, denominadas por los funcionarios como sustentables y aquellas que se reducen meramente a ser canales de transferencia de recursos para la contención de los individuos, consideradas como precarias o inviables. De esta manera, el Estado justificó la redirección de los recursos y desatención sobre estas últimas, bajo el argumento de una mayor eficacia en la utilización de los recursos.

Por otro lado, a principios de 2017 se produjeron modificaciones en la organización del Ministerio de Desarrollo Social (mediante el Decreto 78/2017). Bajo la nueva orientación de la gestión de políticas sociales, se observa un debilitamiento de la promoción del cooperativismo y los componentes asociativos de estas experiencias, orientándose hacia la responsabilización individual y la transferencia individualizada de los destinatarios (Hopp, 2017; Gamallo, 2017). En esta dirección, los dispositivos estatales van a recuperar prerrogativas del programa neoliberal vinculados con el desarrollo del emprendedurismo de enfoque individualista, generando un profundo retroceso de la acción estatal en la promoción de la economía social y solidaria.

Para el caso de los Programas de cooperativas Ingreso Social con Trabajo (PRIST-AT y Ellas Hacen) se destaca que durante 2017 sus partidas presupuestarias prácticamente se duplicaron con respecto a lo ejecutado en 2015, ampliando la cobertura territorial y mejorando su participación en la estructura presupuestaria del MDS. Asimismo, se produjeron ingresos de nuevos beneficiarios como resultado del acuerdo entre el gobierno nacional y las organizaciones populares, como parte de la negociación por la ley de emergencia anteriormente referida. Sin embargo, cómo decíamos la transferencia pasó a denominarse "Subsidio Personal por Capacitación» y ya no comportaba un incentivo para la generación de puestos de trabajo en cooperativas (Gamallo, 2019). De esta manera, se desactivaron progresivamente los componentes asociativos y de promoción comunitaria. 


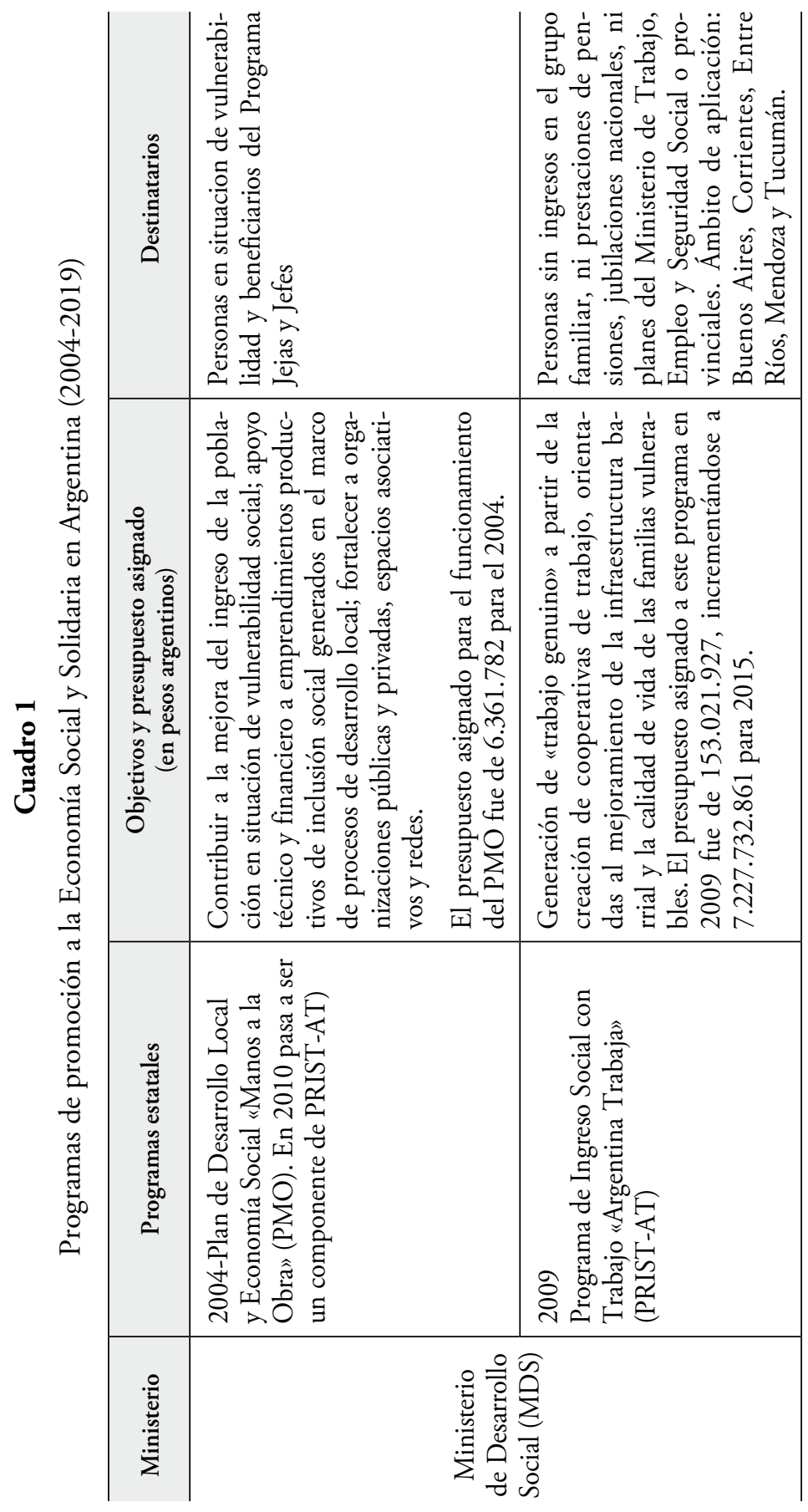


SOFÍA MAGALI VITALI BERNARDI, LEILA OULHAJ

\begin{tabular}{|c|c|c|c|}
\hline 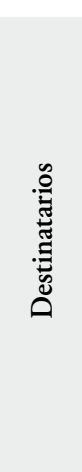 & 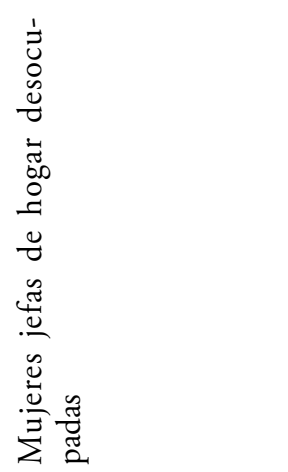 & 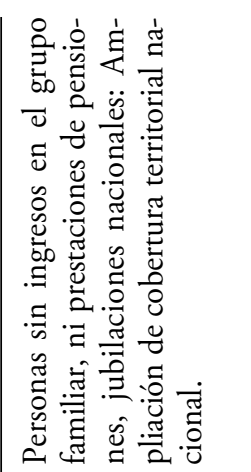 & 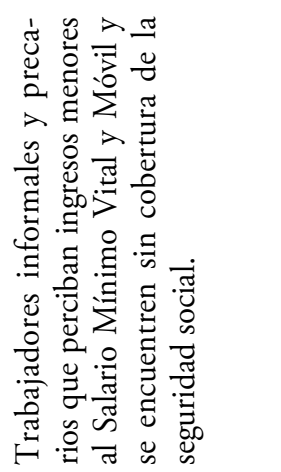 \\
\hline 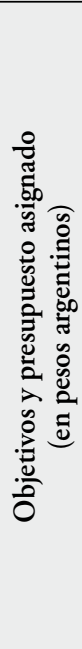 & 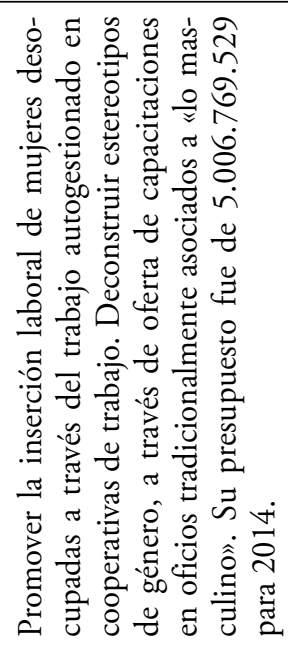 & 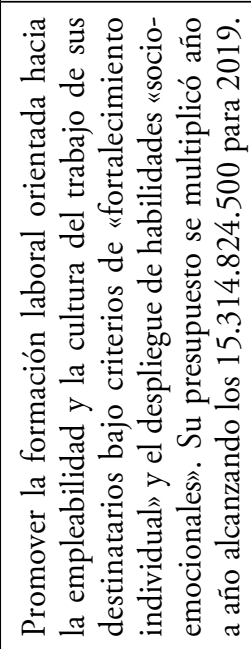 & 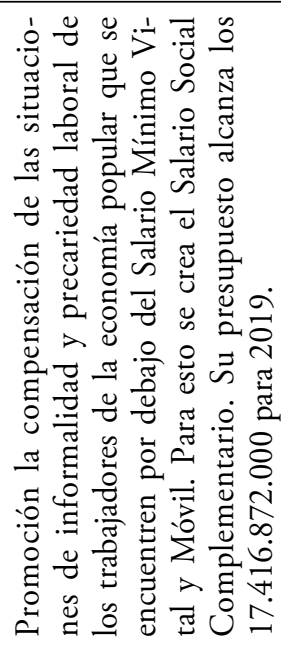 \\
\hline 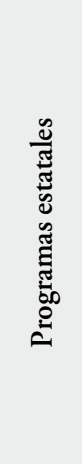 & 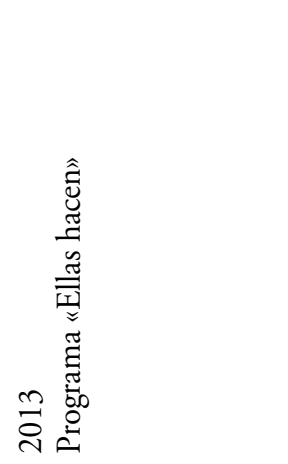 & 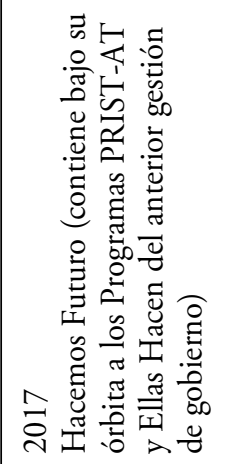 & 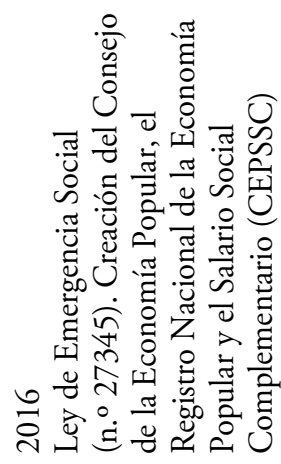 \\
\hline 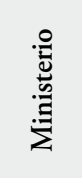 & \multicolumn{3}{|c|}{ 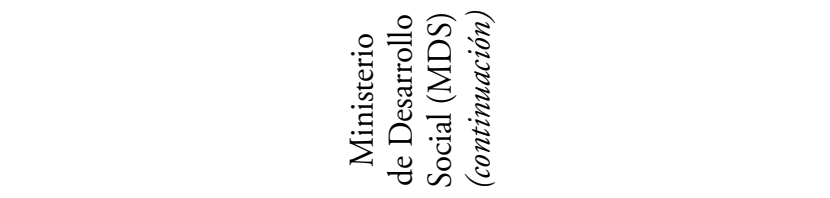 } \\
\hline
\end{tabular}


LA «ECONOMÍA SOCIAL Y SOLIDARIA» ENTRE LA RESTAURACIÓN NEOLIBERAL Y LOS GOBIERNOS...

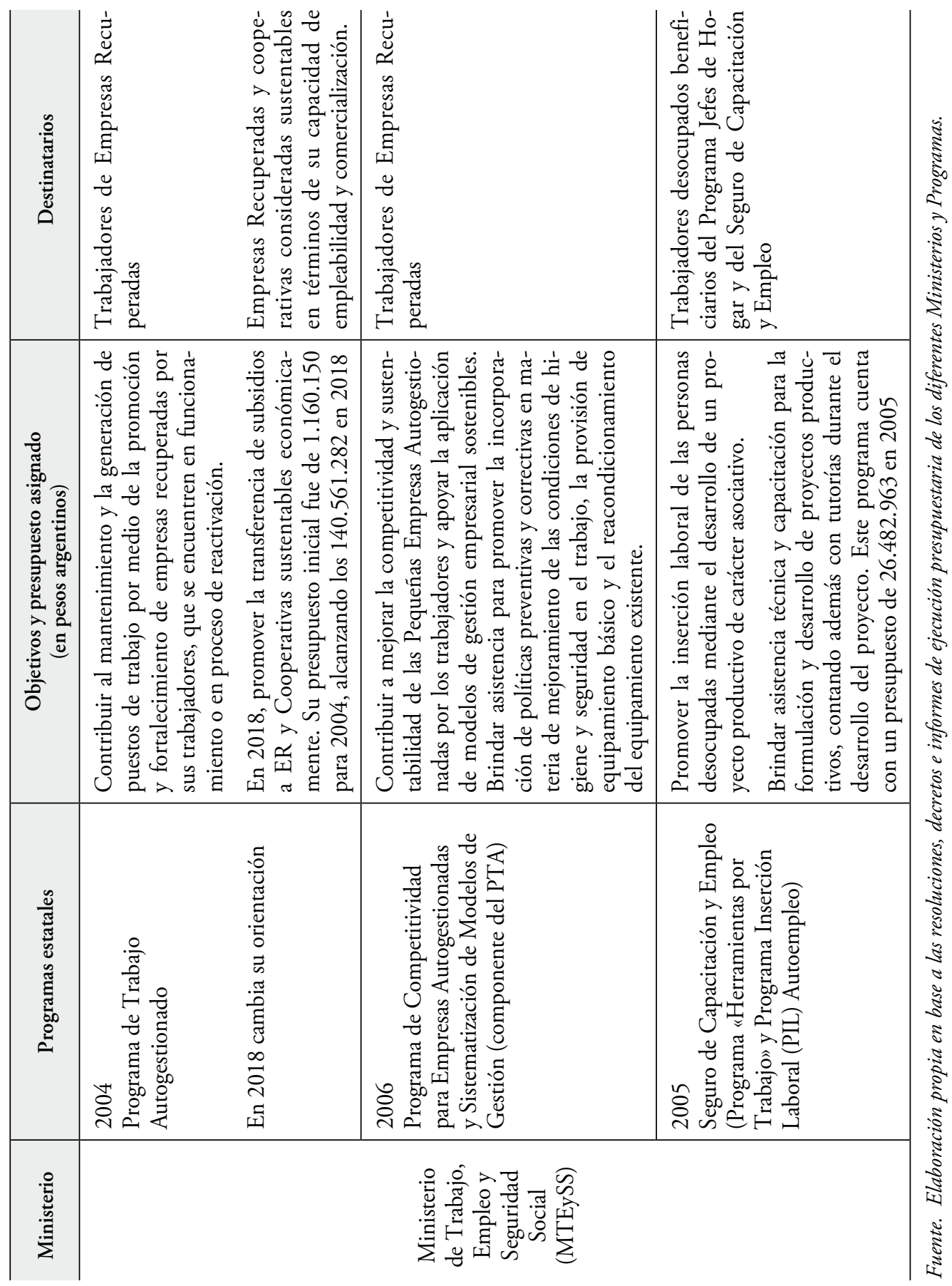


Bajo esta nueva orientación ambos programas comenzaron a promover la formación laboral orientada hacia la empleabilidad y la cultura del trabajo de sus destinatarios y eliminaron la figura de la cooperativa como organizadora de las tareas que se realizan en el marco de los programas (Hopp, 2017). A la vez, las capacitaciones renovaron sus contenidos y se vincularon con el fortalecimiento individual y el despliegue de habilidades socio-emocionales (Decreto 78/2017). La incoherencia originaria entre la autogestión y el discurso del capital humano se inclinó hacia el último incorporando una vuelta de tuerca al paradigma de la activación. A finales de 2018, estos programas fueron reemplazados por Hacemos Futuro, el cual consiste en una transferencia de ingresos que requiere como contraprestación la capacitación laboral y la finalización de la escolaridad.

A partir del recorrido realizado, podemos plantear que la estrategia desplegada en torno a las políticas relacionadas a la ESyS bajo el gobierno de Cambiemos no puede entenderse por fuera de los reclamos y disputas generadas con las organizaciones que nucleaban a gran parte de estas experiencias autogestivas en el país. Asimismo, observamos cómo estos dispositivos fueron utilizados para atenuar el impacto del aumento de la inflación, la devaluación de la moneda y el desempleo como también para contener posibles conflictos sociales de los sectores afectados. En tal sentido, el gobierno avanzó en la concesión de diferentes reivindicaciones como fue la sanción de la Ley de Emergencia Social (n. ${ }^{\circ}$ 27345) y los aumentos de las partidas presupuestarias para los principales programas pre-existentes pero también realizó transformaciones de fondo en sus orientaciones políticas. Como hemos descrito, entre las principales modificaciones en las orientaciones y modalidades de implementación, se tendió al pasaje del fomento de cooperativas hacia transferencias de ingresos orientadas a la empleabilidad individual sobre poblaciones con dificultades de inserción laboral, recolocando la responsabilidad en el individuo, sin garantizar la efectiva incorporación al mercado laboral, ni problematizar desigualdades persistentes (Hopp, 2018).

\section{El caso de México: el inicio de la institucionalización de la «ESyS durante el neoliberalismo «abierto» $y$ sus transformaciones recientes}

A continuación, nos interesa reconstruir el proceso tensional vinculado al surgimiento de diversas políticas estatales de la ESyS mexicana, la cual de manera muy llamativa y, al contrario de Argentina, inicia durante lo que denominaremos el régimen neoliberal «abierto». Es importante destacar que el programa neoliberal en este país tuvo una larga continuidad bajo 
sucesivos gobiernos desde 1982 a 2018. Sus inicios se producen bajo el gobierno de de la Madrid (PRI) entre 1982 y 1988, adquiriendo las mayores prerrogativas de dicho programa con la presidencia de Salinas de Gortari (PRI) a partir de 1988 con una alianza con el Partido Acción Nacional (PAN). En 2000, luego de 7 sexenios en el poder, el PRI fue derrotado por el PAN, partido de la derecha, el cual ejerció el poder durante dos sexenios (entre 2000 y 2012), bajo las presidencias de Vicente Fox Quesada y Felipe Calderón Hinojosa. En 2012, el PRI recupera el poder con Enrique Peńa Nieto (2012-2018).

Recién en 2018, y bajo una retórica del «fin del neoliberalismo en México» asume el poder López Obrador, tras obtener el 53\% de los votos, frente a los partidos que hegemonizaban la arena electoral mexicana. $\mathrm{Su}$ programa de gobierno se autodenominó "cuarta transformación (4T)» y anunciaba entre sus pilares la pelea anticorrupción (entendida no como un crimen individual sino como una economía política específica); una visión neodesarrollista y nacionalista del rol del Estado en la economía y; situar en el centro de la acción de gobierno al bienestar de las personas excluidas (Ackerman, 2020). Sin embargo, en este artículo afirmamos que si bien los gobiernos de 2006-2012 (PAN) y 2012-2018 (PRI), son abiertamente neoliberales, desde finales de 2018, lejos de darse fin a este régimen se expresan claras líneas de continuidad más allá de algunas transformaciones. Para entender esta postura, podríamos mencionar que el nuevo mandatario, López Obrador, de discurso nacionalista y antineoliberal, aceptara e incluso reivindicara el nuevo acuerdo $\mathrm{T}-\mathrm{MEC}^{13}$, lo cual obedece a la gran dependencia de la economía mexicana con respecto a EEUU, y los reducidos márgenes de maniobra que encuentra el nuevo mandatario debido a los factores descriptos. Según diferentes analistas mexicanos, ciertas condiciones del T-MEC son muy perjudiciales para ese país, sumado a la guerra comercial trumpista. Entre sus desventajas se encuentra que las exportaciones de acero mexicanas se han visto disminuidas frente a un aumento de importación de metal estadounidense, siendo más barato comprarlo a EEUU que vender el propio, cuando México venía teniendo ganancias en ese rubro. El sector agropecuario también se ha visto expuesto a una com-

13 Tratado entre México, Estados Unidos y Canadá (T-MEC, o USMCA por sus siglas en inglés) se produce en el marco de la "guerra comercial global» desatada desde marzo de 2018 por el mandatario estadounidense, Donald Trump en base a la doctrina America First («Estados Unidos primero»), y el giro proteccionista en nombre de la «seguridad nacional» estadounidense, en pos de retener la preeminencia mundial de forma unilateral, asegurando una sólida base industrial, disputando el liderazgo en la nueva revolución tecnológica e industrial en curso y buscando impedir el ascenso de los polos de poder alternativos, en particular China (Merino, 2019) 
petencia desigual con sus pares de EEUU, incluso subsidiados por su gobierno. Por otro lado, desde el inicio la 'política migratoria' que ha sido en realidad poner México al servicio de la política migratoria estadunidense (sin respeto de los derechos humanos de las y los migrantes, poniendo todo en marcha, incluyendo la guardia nacional, para impedir a las personas migrantes desde Centroamérica de llegar a la frontera entre México y Estados Unidos, recibiendo de vuelta en México a la gente expulsada desde Estados Unidos, etc.).

Finalmente, la prioridad otorgada en el discurso a las personas que viven en condiciones de pobreza y extrema pobreza parece estar enfocada en consolidar programas sociales que sin embargo resultan insuficientes para dignificar sus condiciones de vida y como ha sido planteado por diferentes analistas conformarse como base clientelar del nuevo gobierno (Casar, $2020)^{14}$.

Recuperando elementos de la particular historia política mexicana analizaremos a continuación los diversos dispositivos estatales que consideran a la Economía Social y Solidaria y sus contenidos específicos durante los diferentes gobiernos. Asimismo, plantearemos algunas transformaciones vinculadas al gobierno autodenominado "progresista» de López Obrador, las cuales tienen un carácter provisional en tanto todavía no ha finalizado su mandato.

\subsection{La Ley de Economía Social y Solidaria}

En primer lugar, es importante tener en cuenta que la ESS en México se encuentra reconocida en la propia Constitución Política de los Estados Unidos Mexicanos. En su artículo 25 se reconoce de manera formal la participación del «sector social de la economía», el cual incluye a la ESS, pero no se limita a ella: «Al desarrollo económico nacional concurrirán, con responsabilidad social, el sector público, el sector social y el sector privado, sin menoscabo de otras formas de actividad económica que contribuyan al desarrollo de la Nación». Por lo tanto, si bien ambos términos no pueden ser considerados como sinónimos, es interesante ver que, de una forma u otra, la ESS ha sido tomada en cuenta a nivel constitucional desde hace varias décadas.

Ahora bien, el proceso de institucionalización de la ESS se inicia en 2012, año en la que fue promulgada la Ley de Economía Social y Solidaria

$14 \mathrm{Si}$ bien este tema excede los intereses de nuestro artículo, para profundizar sobre este proceso se siguiere el trabajo de María Amparo Casar (2020). 
o LESS (DOF, 2012), bien que fue revisada varias veces desde entonces: el 24 de enero y 11 de junio de 2013, en 2015 y la última vez en 2019. Es interesante notar que en 2012 gobernaba el Partido de Acción Nacional (PAN), el cual pertenece, como lo hemos mencionado, a la derecha del espectro político. Si bien era su último ańo de gobierno, definitivamente dejará una huella en cómo se entiende la ESS y lo que se busca con ella.

El $1^{\text {ero }}$ de diciembre de 2012, inició el sexenio de Enrique Peńa Nieto del Partido Revolucionario Institucional (PRI) del centroderecha. La última reforma fue aprobada con el gobierno actual, del Movimiento Regeneración Nacional (Morena), autodefinido como de la izquierda pero sus prácticas demuestran una continuidad con la visión política del centroderecha.

La Ley de Economía Social y Solidaria define, en el artículo tercero, a la ESS como

[...] el sector de la economía a que se refiere el párrafo octavo del artículo 25 de la Constitución Politica de los Estados Unidos Mexicanos, el cual funciona como un sistema socioeconómico creado por organismos de propiedad social, basados en relaciones de solidaridad, cooperación y reciprocidad, privilegiando al trabajo y al ser humano, conformados y administrados en forma asociativa, para satisfacer las necesidades de sus integrantes $y$ comunidades donde se desarrollan, en concordancia con los términos que establece la presente Ley.

En el artículo cuarto se precisan las diferentes formas de organización que pertenecen a este "sector social de la economía» mexicana: " [...] comunidades; organizaciones de trabajadores; sociedades cooperativas; empresas que pertenezcan mayoritaria o exclusivamente a los trabajadores; $y$ en general, de todas las formas de organización social para la producción, distribución y consumo de bienes y servicios socialmente necesarios.»

Consideramos que hay dos problemas de fondo con esta Ley y, por lo tanto, con uno de los pasos iniciales para la institucionalización de la ESS mexicana. El primero está relacionado con la falta de figuras jurídicas propias a las múltiples realidades de las instituciones de la ESS y, de ahí, la dificultad por parte de los actores colectivos, de optar por una figura que responda claramente a sus realidades y necesidades. Tal vez uno de los ejemplos más evidentes reside en las cooperativas de ahorro y préstamo (CAP) (véase Oulhaj, 2016).

Hemos aquí una de las principales diferencias entre ambos países estudiados en este artículo: en México, el proceso de institucionalización de la ESS no se ha dado con base en las demandas y las realidades de sus actores. Como lo precisó Rendón Corona (2014, p. 46), la LESS resulta de la 
iniciativa de dos senadores y «no fue el producto de una amplia consulta entre los involucrados en el mundo de la economía social y solidaria [...] ni se sometió al escrutinio de la opinión pública, por lo que nació sin una base de legitimidad social».

Consideramos que esto último puede vincularse con las particulares características del sector de la Economía Social y Solidaria en México, los cuales se enmarcan principalmente al interior del movimiento indígena y campesino, quienes históricamente han luchado por mayores niveles de independencia y autonomía, esta última no sólo en la autogestión productiva sino en la cultura y el autogobierno (Marañon, 2015). En esta línea, se destaca que estos sectores, desde los años ochenta, han desarrollado intensas luchas por su autonomía, las cuales rebasaron la pelea por la autoadministración socioeconómica para orientarse hacia la posibilidad de autodeterminación. Bajo esta reivindicación se ha recuperado por ejemplo el autogobierno a nivel comunitario, el cual de acuerdo con sus propias normas, usos y costumbres, recupera la historia de los pueblos precolombinos y se perfilan hacia prácticas antisistémicas, por la cual los oprimidos se resisten construyendo órdenes de organización alternativos (Bartra y Otero, 2008). Con esto no pretendemos negar la existencia de diferentes demandas al Estado en busca de diversos apoyos (crédito, asistencia técnica, regulación de precios de los productos, desarrollo de infraestructura de transporte y comunicaciones), pero si resaltar que se constituyen como sectores de mayor autonomía que en el caso Argentino.

El segundo problema de la Ley de Economía Social y Solidaria reside en su falta de conceptualización. Si bien su título es Ley de Economía Social y Solidaria, en su texto no se menciona más este concepto sino solamente el de "Sector Social de la Economía» (cuando ambos términos no son sinónimos). Más aún, a la hora de enumerar las organizaciones que participan del «sector social de la economía» parece orientarse de manera sectorial, aunque con especificidades propias de su historia económica, como es el caso con los ejidos (Guerra, 2012). La inexistencia de un marco conceptual propio a la ESS (que permita estructurar de manera consistente los elementos y características de los entes que la conforman) es una de las barreras que no han permitido su desarrollo integral. De hecho, es fundamental subrayar que la ESS en este país no ha tenido un mayor empuje como ha sido en otros, incluyendo Argentina.

¿Qué nos dice esta ley en cuanto a las políticas de igualdad de género en la ESS? En su artículo 8, en el apartado sexto, se precisan los fines 'del sector social de la economía', entre los cuales se indica: «Facilitar a los Asociados de los Organismos del Sector la participación y acceso a la formación, el trabajo, la propiedad, la información, la gestión y distribución equitativa de beneficios sin discriminación alguna». En el décimo artículo 
se determinan los valores de los organismos de este sector, entre los que destacan la equidad e igualdad. Sin embargo, no se precisa ninguna meta para alcanzar una paridad entre hombres y mujeres en los puestos directivos, ni para garantizar mayores condiciones de equidad entre hombres y mujeres y mucho menos plantea llegar a una igualdad en la materia a largo plazo en las prácticas de la ESS. Vale la pena mencionar que el gobierno actual (2018-2024) aprobó la reforma constitucional en materia de igualdad y paridad de género en los tres ámbitos de gobierno y ésta debería empezar a permear otro tipo de instituciones, cuestión que será interesante ver si al fin de su sexenio, se podría hacer un balance positivo de esta reforma.

Podemos observar de entrada en relación con la LESS, un discurso de la ESS desde lo estatal y no planteado desde sus actores y sus prácticas, y aún peor, una búsqueda de control. Como destaca Rendón Corona (2014)

Diversas organizaciones cooperativistas y asociativas se reunieron a discutir el texto de 2012 y expresaron cierto recelo sobre la pérdida de autonomía. De sus puntos de vista surgió la impresión de que se aceptaba como algo deseable, pero objetaban al menos tres cuestiones: el control de las finanzas de los organismos, la intromisión en la vida de las organizaciones y la falta de participación del sector social en la toma de decisiones. (p. 48)

Analizar si existen divergencias entre dos gobiernos (de orientación diferentes por los discursos planteados) en término de políticas públicas en esta materia resulta interesante a la hora de hablar de un país gobernado desde diciembre de 2018 por un gobierno progresista. De hecho, el actual gobierno enfatiza, como en el Plan Nacional de Desarrollo, que en México ya no se aplica el programa neoliberal. Surge la pregunta de entender la diferencia en cuanto a la importancia otorgada a la ESS entre el gobierno anterior (neoliberal) y el de López Obrador (progresista) para entender si es al nivel de esta otra economía, que podemos ver un cambio de programa económico, otorgando más importancia a la ESS o al menos a las cooperativas, cualquier sea su sector de actividad.

Para lograrlo, analizaremos brevemente el Plan Nacional de Desarrollo de ambos sexenios, el Plan Sectorial de las secretarías relacionadas con la ESS y el Programa de Fomento a la Economía Social.

\subsection{El Plan Nacional de Desarrollo 2013-2018 en el marco del programa neoliberal}

Después de la promulgación de la LESS, el segundo paso en el proceso de institucionalización de la ESS se da con el Plan Nacional de De- 
sarrollo (PND) del gobierno de Enrique Peña Nieto. Lejos de consolidar este proceso de institucionalización, este representó un paso más en la confusión conceptual mencionada anteriormente: la ESS como tal no aparecía en el PND 2013-2018 del Gobierno de la República de México de Enrique Peña Nieto, sino el término de Rendón «economía social». Este es un primer elemento que debemos subrayar de entrada: si bien hay una Ley de Economía Social y Solidaria, en el PND se optó por usar el término de «economía social», un concepto utilizado en varios países europeos y en la Unión Europea de manera general. Para América Latina, las prácticas de los sectores populares de varios países han sido reflejadas utilizando más bien los conceptos de economía solidaria (Gaiger, 2007), economía popular y/o economía del trabajo (Coraggio, 2008) o más recientemente como economía social y solidaria (Pérez de Mendiguren y Etxezarreta, 2015).

En la estrategia 4.8.5 del PND 2013-2018, y titulada «Fomentar la economía social», se mencionan dos líneas de acción clave. La primera se enfoca en «realizar la promoción, visibilización, desarrollo y cooperación regional e intersectorial de las empresas de la economía social, para mitigar las diferentes formas de exclusión económica y productiva». Y la segunda línea, en «Fortalecer las capacidades técnicas, administrativas, financieras y gerenciales de las empresas de la economía social» (Gobierno de la República, 2013: 140). Llama la atención que en ambas líneas de acción se mencionan a las «empresas de la economía social», cuando el conjunto de las prácticas populares pertenecientes a la ESS han sido puesta en marcha por actores colectivos organizándose para responder a las necesidades básicas de la población con base en diversos esquemas de organización (que no son solamente los del emprendimiento, el cual ni siquiera representa la forma de organización predominante). Este primer elemento es interesante: el emprendimiento es el que muchas veces se considera en las políticas públicas desde ya varias décadas y en particulares las que son «formales».

El planteamiento de la política de economía social del Gobierno Mexicano entre 2012 y 2018 ha sido influido sin duda alguna de manera directa por la Unión Europea. Hacemos está afirmación con base a la «Resolución sobre la Promoción de la Economía Social» en Europa aprobada por el Consejo Europeo el 7 de diciembre del 2015. En esta misma resolución se reconoce el papel de la economía social en conseguir

un crecimiento inteligente, sostenible e integrador, empleo de alta calidad, cohesión social, innovación social, desarrollo local y regional, y protección del medio ambiente [...] Y algo aún más relevante, la economía social es un sector que ha capeado la crisis económica mucho mejor que otros sectores y cada vez se reconoce más su papel a nivel europeo. (Consejo de la Unión Europea, 2015) 
Entre las medidas que propone el Consejo de la Unión Europea se menciona el «mejorar la visibilidad de la economía social y del impacto que esta tiene en la sociedad, para garantizar un conocimiento suficiente que ayude a la formulación de políticas públicas». Esta medida es la primera línea de acción mencionada en el PND 2013-2018 en México («realizar la promoción, visibilización, desarrollo y cooperación regional e intersectorial de las empresas de la economía social, para mitigar las diferentes formas de exclusión económica y productiva»). El Consejo de Europa reconoce también la importancia de contar con marcos jurídicos sólidos y globales que permite aumentar el potencial de las empresas de economía social e incrementar al máximo su incidencia social positiva en cuanto al empleo y crecimiento. En México, hemos observado que en el caso de los «Apoyos en efectivo para proyectos productivos», estos son mayores si las Organizaciones del Sector Social de la Economía (OSSE) están legalmente constituidas.

\subsection{El Plan Sectorial de las Secretaría de Economía y después de Desarrollo Social}

Para entender el lugar ocupado por la ESS en la política pública federal, hemos optado por revisar el plan sectorial de la Secretaría de la que dependía. En el sexenio de Peña Nieto, primero fue en la Secretaría de Economía y el plan fue llamado «Programa de Desarrollo Innovador 2013-2018». Entre sus objetivos explícitos se manifiesta «Impulsar a emprendedores y fortalecer el desarrollo empresarial de las Mipymes [Micro, pequeñas y medianas empresas] y los organismos del sector social de la economía», para lo mismo se propone «Incrementar las oportunidades de inclusión productiva y laboral en el sector social de la economía». En los fragmentos seleccionados se destaca como aparecen otros conceptos como «el sector social de la economía»; las «Mipymes»; y, los "proyectos productivos». De esta manera, se sigue observando la confusión entre las prácticas de los actores de la ESS con las empresas (en este plan sectorial se precisa que están en el nivel de las Mipymes), con proyectos productivos y, como en el caso europeo, se están viendo como una opción para incluir laboralmente a las personas excluidas.

Ahora bien, para lograr este objetivo sectorial, desde el sexenio anterior, el Ejecutivo Federal diseñó el Programa de Fomento a la Economía Social (PFES). Este programa fue ordenado por la LESS en 2012, y comienza a operar de forma anual en 2014 y en 2015 inicia el de mediano plazo. Si bien este programa representaba otro paso hacia la institucionalización de la ESS, contó con un presupuesto insuficiente, lo que restringió su capacidad de acción y por lo tanto sus impactos no han sido significativos ni llevó a la consolidación de organizaciones de esta otra economía. 
El PFES 2015-2018 se propone «Contribuir a mejorar el ingreso de personas en situación de pobreza mediante el fortalecimiento de capacidades y medios de los Organismos del Sector Social de la Economía, así como de las personas con ingresos por debajo de la línea de bienestar integradas en grupos sociales, que cuenten con iniciativas productivas» (Gobierno de la República). De manera específica, el Programa buscaba «Fortalecer capacidades y medios de los Organismos del Sector Social de la Economía, así como de las personas con ingresos por debajo de la línea de bienestar, integradas en grupos sociales que cuenten con iniciativas productivas para la inclusión productiva, laboral y financiera» (Gobierno de la República). En relación a esto último se destaca que al igual que para el caso argentino las herramientas de la ESyS son incorporadas al interior de las políticas sociales en búsqueda de generar mecanismos de inclusión para la población que vive en condiciones de pobreza y extrema pobreza. Sin embargo, en la experiencia mexicana no se dieron los medios presupuestarios necesarios, aunque el país contaba con una población de 55,3 millones de personas que vivía en condiciones de pobreza y 11,4 millones en extrema pobreza (Coneval, 2015).

El Programa de Fomento a la Economía Social cuenta con tres modalidades de apoyo, las cuales reflejan sus principales ejes de trabajo: los Proyectos Productivos; el Desarrollo de Capacidades; y la Banca Social. Para entender el orden de importancia de estas tres modalidades, hemos revisado el porcentaje del presupuesto ejercido destinado a cada una entre 2015 y 2018. Se observa una estrategia orientada casi por completo hacia los «Proyectos Productivos»: ya que representó más del 90\% del gasto total de las tres modalidades, seguida de muy lejos por la Banca Social y en tercer lugar por el desarrollo de capacidades.

Por la importancia que tiene el apoyo a proyectos productivos, vale la pena precisar algunos elementos en relación a este. Había dos unidades responsables de los apoyos a proyectos productivos entre 2015 y 2018: la Dirección General de Opciones Productivas (DGOP) y el Instituto Nacional de la Economía Social (Inaes), ambas de la Secretaría de Desarrollo Social desde junio de este 2016. La DGOP se encargaba de la modalidad "Apoyos para Impulso Productivo», la cual consistía en apoyos económicos "para proyectos productivos que promuevan la reinversión de los ingresos generados por el proyecto, dirigidos a personas con ingresos por debajo de la línea de bienestar conformados en grupos sociales [...]». El Inaes era, por su parte, responsable de los Apoyos en efectivo para

la ejecución de un proyecto productivo nuevo; para el desarrollo y consolidación de un proyecto en operación, o para la vinculación en redes o cadenas de valor. [Podian] ser otorgados para inversión fija, inversión diferida y/o capital de trabajo; o para la adquisición de componentes de inversión individua- 
les o la constitución de garantías líquidas que respalden de manera complementaria un crédito [...]. (Inaes)

Entre 2015 y 2018, gran parte de los apoyos para proyectos productivos fueron destinados a la ejecución de un proyecto nuevo. Los montos por tipos de apoyos a proyectos productivos, dependían si se trataban de apoyos para Impulso Productivo o bien Apoyos en efectivo para proyectos productivos. Llama la atención que si las OSSE estaban legalmente constituidas, el monto máximo era mucho más elevado. Este tema ha sido un eje fuerte del Banco Mundial pero también del gobierno mexicano para aumentar la recaudación hacia este tipo de institución.

\subsection{El lugar ocupado por la ESS bajo el gobierno de López Obrador. Algunos comentarios provisionales}

A continuación presentaremos algunas transformaciones y continuidades presentes en los dispositivos estatales vinculados a la ESyS durante el gobierno de López Obrador, las cuales, como precisamos anteriormente, tienen un carácter provisional en tanto su mandato se encuentra en curso.

Resulta importante destacar que si bien es un gobierno que alcanzó su triunfo electoral bajo una proclama enfática sobre el cambio de rumbo y alejamiento del programa neoliberal, todavía resultan insuficientes las medidas tomadas al respecto. En este sentido, en lo que respecta al Plan Nacional de Desarrollo (2019-2024), se manifiesta que este:

[...] tendrá carácter histórico porque marcará el fin de los planes neoliberales y debe distanciarse de ellos de manera clara y tajante; esto implica, en primer lugar, la restitución de los vinculos entre las palabras y sus significados $y$ el deslinde con respecto al lenguaje oscuro y tecnocrático que, lejos de comunicar los propósitos gubernamentales, los escondía. (PND 2019-2024 p. 7)

Bajo esta nueva retórica sin embargo se observa que en el PND, la economía social no se menciona explícitamente, encontrando en cambio los términos de «economía para el bienestar» y el «Banco del Bienestar». Estas nuevas nominaciones, sin embargo, no modifican sustancialmente las orientaciones del programa económico implementado en el marco de gobiernos que describimos dentro del programa neoliberal. En lo que respecta al Banco del Bienestar, este tiene como propósito principal «ofrecer servicios bancarios a los beneficiarios de los programas sociales y eliminar el manejo de dinero en efectivo en la dispersión de los recursos de tales programas. De esta forma se eliminará la posibilidad de que se generen prácti- 
cas corruptas o clientelares en el manejo de los apoyos» (PND 2019-2024 pp. 52). Detrás del discurso de la búsqueda de terminar con la corrupción, parece que en realidad se busca incluir al mercado a los beneficiarios de los programas sociales, es decir en teoría los más pobres del país, promoviendo el crédito, nada novedoso o distante de lo que hace un gobierno neoliberal o bien organismos como el Banco Mundial.

En cuanto al Programa de Fomento a la Economía Social bajo gobierno actual, es importante destacar que este deja de ser parte de la Secretaría de Economía (como lo fue durante su primera etapa de la gestión de Peña Nieto) y de la Secretaria de Desarrollo (como lo fue desde 2016) para quedar bajo la órbita de la Secretaría de Bienestar. Este cambio resulta importante en tanto permite acentuar el carácter tendiente hacia fines sociales y no meramente económicos para la promoción de las actividades enmarcadas en este programa. Sin embargo, es importante seguir de cerca su evolución en tanto no queda muy claro si se pretende dar las herramientas para que las personas pobres se incorporen a este mercado y/o se beneficien de un apoyo "clientelar", como se ha observado con otros programas que dependen de la Secretaría de Bienestar.

Esto último se vincula con que más allá de este cambio se destacan claras líneas de continuidad con los planteos precedentes. Tal como describimos anteriormente, el objetivo general del mismo plantea: «Fortalecer la inclusión productiva, financiera y al consumo así como el encadenamiento productivo de los Organismos del Sector Social de la Economía (OSSE) mediante el desarrollo de sus capacidades para contribuir a la construcción del bienestar social desde las prácticas y los principios de la Economía Social y Solidaria». Por su parte, el objetivo específico del PFES está formulado como sigue: «Fortalecer capacidades y medios de los Organismos del Sector Social de la Economía, que cuenten con iniciativas productivas para la inclusión productiva y financiera». Se observa claramente un enfoque hacia los proyectos productivos y la inclusión (productiva y financiera), el cual está promovido por el Banco Mundial.

Se específica asimismo lo siguiente:

El programa tendrá una cobertura nacional, con base en la disponibilidad presupuestal, otorgando prioridad a los Organismos del Sector Social de la Economía ubicados en municipios que cumplan con las siguientes caracteristicas: de mayor marginación, mayor presencia de población indígena y/o afromexicana, y considerando altos indices de violencia, asimismo se atenderá a poblaciones que se encuentren en alguna situación de emergencia nacional. (Programa de Fomento a la Economía Social, 2018)

Si bien el gobierno se plantea como opuesto al anterior, hay puntos en común en cuanto a este programa, sus objetivos y cobertura. También los 
podemos subrayar al momento de mirar a las tres modalidades de apoyo del PFES, las cuales reflejan sus principales ejes de trabajo: los Proyectos Productivos; el Desarrollo de Capacidades; y la Banca Social. Con la actual administración, no se ven varios cambios en los apoyos económicos para la implementación, desarrollo, consolidación y crecimiento de proyectos de economía social para la producción y el consumo, a partir del trabajo colectivo; apoyos para el desarrollo de capacidades; y apoyos para la Banca Social.

\section{Cuadro 2}

Programas de promoción a la Economía Social y Solidaria en México (2015-2019)

\begin{tabular}{|c|c|c|c|c|}
\hline Período & $\begin{array}{c}\text { Secretarías y } \\
\text { programas }\end{array}$ & Objetivos & \multicolumn{2}{|c|}{$\begin{array}{l}\text { Datos presupuestarios } \\
\quad(\text { pesos MXN) }\end{array}$} \\
\hline $\begin{array}{l}\text { Sexenio de Peńa } \\
\text { Nieto }\end{array}$ & $\begin{array}{l}2015-2018 \\
\text { Secretaría de } \\
\text { Economía. } \\
\text { Programa de } \\
\text { Fomento a la } \\
\text { Economía Social }\end{array}$ & $\begin{array}{l}\text { Contribuir a mejorar } \\
\text { el ingreso de personas } \\
\text { en situación de pobreza } \\
\text { mediante el fortale- } \\
\text { cimiento de capaci- } \\
\text { dades y medios de los } \\
\text { OSSE, así como de las } \\
\text { personas con ingresos } \\
\text { por debajo de la línea } \\
\text { de bienestar integradas } \\
\text { en grupos sociales, que } \\
\text { cuenten con iniciativas } \\
\text { productivas }\end{array}$ & $\begin{array}{l}2015 \\
2016 \\
2017 \\
2018\end{array}$ & 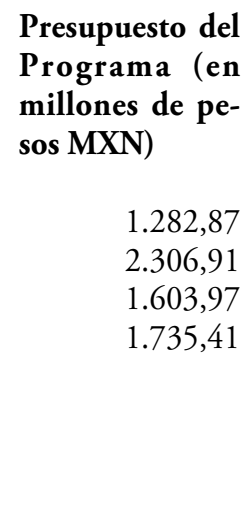 \\
\hline $\begin{array}{l}\text { Inicio sexenio } \\
\text { López Obrador }\end{array}$ & $\begin{array}{l}2019 \\
\text { Secretaría de } \\
\text { Bienestar. } \\
\text { Programa de } \\
\text { Fomento a la } \\
\text { Economía Social }\end{array}$ & $\begin{array}{l}\text { Fortalecer la inclusión } \\
\text { productiva, financiera } \\
\text { y al consumo así como } \\
\text { el encadenamiento pro- } \\
\text { ductivo de los Organis- } \\
\text { mos del Sector Social } \\
\text { de la Economía (OSSE) } \\
\text { mediante el desarrollo } \\
\text { de sus capacidades para } \\
\text { contribuir a la construc- } \\
\text { ción del bienestar social } \\
\text { desde las prácticas y los } \\
\text { principios de la Econo- } \\
\text { mía Social y Solidaria }\end{array}$ & Año & $\begin{array}{l}\text { Presupuesto del } \\
\text { Programa (en } \\
\text { millones de pe- } \\
\text { sos MXN) } \\
\qquad 491.610\end{array}$ \\
\hline
\end{tabular}

Fuente. Elaboración propia en base a resoluciones y decretos de los diferentes Ministerios y Programas e informes del Consejo Nacional de Evaluación de la Politica Pública de Desarrollo Social. 
En cuanto al presupuesto del gobierno actual al PFES, registramos una drástica caída. En su primer año de gestión se redujo el presupuesto asignado de 2.112.387,829 a 491.610,00 pesos MXN, esta cantidad es inferior al 0,01\% del Presupuesto de Egresos de la Federación (PEF) 2019. De esta manera, podemos afirmar que la Economía Social y Solidaria no parece ser una prioridad para el gobierno de Andrés Manuel López Obrador.

A modo de síntesis podemos plantear que si bien México, a diferencia de otros países latinoamericanos, presenta tanto en su Constitución como en su legislación nacional componentes vinculados al desarrollo de la Economía Social y Solidaria, estos resultan ambiguos tanto en su contenido conceptual como normativo, dificultando su injerencia en el estímulo de experiencias concretas. Consideramos que esto se vincula al escaso lazo de estas iniciativas estatales con las demandas de los actores y sectores populares que buscan responder a través de prácticas colectivas solidarias, a sus necesidades. Por el contrario, hemos destacado como su diseño recupera prerrogativas del modelo europeo, sin tomar en cuenta las realidades de este sector en el país y de su evolución a través de las últimas décadas. Tampoco, se busca una verdadera solución a la situación de pobreza y extrema pobreza vivida por la gran parte de la población en el país, ya que los montos presupuestarios resultan sumamente escasos. La prioridad es otra, es convertirlos en consumidores del mercado global.

En lo que respecta al Programa de Fomento a la Economía Social hemos observado como el mismo se utiliza tanto como una herramienta de inclusión social de los sectores empobrecidos y excluidos del mercado de trabajo, como también para la promoción de proyectos productivos legalmente constituidos, principalmente de pequeños y medianos productores para insertarlos al mercado.

Finalmente, en lo que respecta a las transformaciones y continuidades registradas durante los gobiernos neoliberales y progresistas, identificamos que hasta el momento se han dado claras líneas de continuidad en sus contenidos y componentes, pero con una importante caída presupuestaria bajo el último gobierno.

\section{Reflexiones finales}

Para finalizar este artículo nos interesa puntualizar los principales hallazgos realizados en relación a las divergentes políticas vinculadas a la ESS en México y Argentina ponderando las especificidades de cada caso. En primer lugar, observamos que mientras en Argentina las iniciativas estatales de ESyS emergen durante 2003 como respuesta a la alta conflictividad que protagonizaban los movimientos de trabajadores desocupados y 
del sector informal urbano luego de la crisis política de 2001; en México se desarrollan como propuestas estales pensadas desde arriba, sin el suficiente debate y consecuente apoyo popular.

En esta línea, hemos observado que para el primero estas se desarrollan al calor de las demandas populares de numerosos tipos de organizaciones, movimientos sociales, entre los que despuntaron los movimientos de trabajadores desocupados y las denominadas Empresas Recuperadas (ER) que impugnaban al Estado por la creación y/o mantenimiento de puestos de trabajo; ayuda social para los hogares de desocupados; y más tardíamente por el reconocimiento y aumento de vacantes en los programas de empleo y creación de cooperativas de trabajo. La gravitación de estos sectores y sus demandas es una de las claves explicativas que permite entender cómo, más allá de la precariedad institucional con el que se desarrollaron estos programas durante los gobiernos kirchneristas, estas se mantuvieran más allá de algunas modificaciones durante la «restauración neoliberal» bajo el mandato macrista.

Por el contrario, en el caso mexicano identificamos que el movimiento popular vinculado a la ESyS se enmarcan al interior del movimiento indígena y campesino, los cuales históricamente si bien han demandado al Estado diversos apoyos para lograr la sustentabilidad de sus prácticas económicas, se constituyen como sectores de mayor autonomía del Estado que en el caso Argentino. Consideramos que esto gravitó en el desarrollo independiente de estas políticas a las demandas y necesidades concretas de estos sectores.

Ahora bien, en lo que respecta a sus contenidos e implicancias prácticas, observamos diferentes limitaciones presentes en ambos casos. En el primero estas se orientan a generar fuentes de trabajo para los sectores denominados inempleables a partir de su inserción en otras formas productivas (cooperativas y emprendimientos productivos). De esta manera, si bien sus acciones tendieron a la promoción del trabajo como garantía de inclusión social lo hicieron sin intervenir ni superar las condiciones de precariedad de los trabajadores autogestionados. Por el contrario, en el caso mexicano estas se orientan principalmente a brindar apoyo a diferentes emprendimientos económicos que se encontraban legalmente constituidos, siendo difícil su acceso para los sectores populares e indígenas. Esto último se vincula con el escaso presupuesto otorgado a estas políticas públicas.

Por otro lado, identificamos que en el caso mexicano se observa un sesgo conceptual más cercano a organismos internacionales como el Banco Mundial y por lo tanto, no logran contener las especificidades y necesidades concretas de los sectores populares de la ESyS.

En ambos casos hemos identificado claras líneas de continuidad en estas políticas más allá del recambió político generado con el arribo al 
poder Mauricio Macri (de sesgo neoliberal) como de López Obrador (de sesgo progresista). Sin embargo, mientras en Argentina durante la nueva gestión se mantuvieron e incluso incrementaron los presupuestos destinados a estas políticas debido a las demandas populares del sector y en tanto fueron herramientas de contención social, en el caso mexicano, se destaca una caída presupuestaria drástica para estas iniciativas. Por otro lado, observamos que, bajo el cambio de gobierno argentino, se modifican las orientaciones y modalidades de implementación, en tanto se elimina el fomento de cooperativas hacia transferencias de ingresos orientadas a la empleabilidad individual sobre poblaciones con dificultades de inserción laboral. Para el caso mexicano, si bien estas políticas pasan a ser parte de una nueva retórica de fin del neoliberalismo, hasta el momento, presentan claras líneas de continuidad en sus dimensiones concretas provisionales.

Finalmente, quisiéramos aportar algunas preguntas e interrogantes que adquieren particular relevancia en el contexto de la pandemia del COVID-19 y la agudización de la crisis multidimensional. En primer lugar, consideramos que será necesario seguir de muy cerca la evolución de estas políticas y su articulación con las demandas populares, en tanto las mismas se consolidan en ambos países como alternativas de vida de grandes porciones de la población empobrecida, más aún en contextos de crisis. Asimismo, ante los retornos de los gobiernos denominados progresistas en ambos países resulta pertinente analizar si los mismos continuarán perpetrando las limitaciones descriptas en estas políticas o lograran encarar las transformaciones necesarias para consolidad diferentes formas de trabajo, más humanas y solidarias para la reproducción digna de la vida.

\section{Bibliografía}

Ackerman, E. (2020). ¿¿Gobierna la izquierda en México? en Revista Jacobin América Latina, (1). Disponible en: https://jacobinlat.com/2020/12/01/gobiernala-izquierda-en-mexico/

Arcidiacono, P. y Bermudez, Á. (2018). «Ellas hacen». Programas sociales y exigencias a las mujeres en Argentina. Revista Estudos Feministas, 26(2), 1-16.

Bartra, A. y Otero G. (2008). Movimientos indígenas campesinos en México: la lucha por la tierra, la autonomía y la democracia. En Sam Moyo y Paris Yeros (coords.), Recuperando la tierra. El resurgimiento de movimientos rurales en África, Asia y América Latina (p. 47-86). Buenos Aires: CLACSO.

Deux Marzi, M. V y Vázquez, G. (2009). Emprendimientos asociativos, empresas recuperadas y economía social en la Argentina. Íconos. Revista de Ciencias Sociales, 33 (1), 91-102. 
Caruana, M. E (2016). Las políticas públicas y su visión de la economía social y solidaria en Argentina. Revista Mexicana de Ciencias Politicas y Sociales Nueva Época, LXI(227), 349-378.

- y Srnec, C. (2014). La Economía Social y Solidaria en América del Sur: la construcción de un nuevo modelo de política social. CESOT. Facultad de Ciencias Económicas. Universidad de Buenos Aires. Recuperado de http://bibliotecadigital.econ.uba.ar/download/docin/docin_cesot_085.pdf

Casar, M.A (2020, 31 de agosto). Programas sociales, clientelismo y corrupción. El Pais, p. 13.

Cepal (2020). Informe especial COVID-19 No 2. Comisión Económica para América Latina y el Caribe. Disponible en: https://repositorio.cepal.org/ bitstream/handle/11362/45445/1/S2000286_es.pdf

Coneval (2020) Informes De Pobreza Y Evaluación De Las Entidades Federativas 2020 Disponible En Https:/Www.Coneval.Org.Mx/Coordinacion/Entidades/Paginas/Informes_Pobreza_Evaluacion_2020.Aspx

Coraggio, J. L. (2014). La presencia de la Economía Social y Solidaria (ESS) y su institucionalización en América Latina. UNRISD United Nations Research Institute for Social Development.

- (2007) «Una perspectiva alternativa para la economía social: de la economía popular a la economía del trabajo». En José Luis Coraggio (Comp.), La economía social desde la periferia. Contribuciones Latinoamericanas. Buenos Aires, ungs - Altamira, 165-194.

Ciolli, V. (2013). El papel de las políticas de Economía Social en la matriz socioasistencial Argentina. Iberofórum. Revista Ciencias Sociales, VIII (15), 31-63.

- (2009) Estado y lucha de clases: una aproximación desde la política social en la Argentina neoliberal. Revista Herramienta. 42. Buenos Aires, Argentina.

Fernández Álvarez M. I. y Manzano, V. (2007): Desempleo, acción estatal y movilización social en Argentina disponible en http://scielo.unam.mx/pdf/polcul/ n27/n27a8.pdf

Gamallo, G. (2019). «Prestaciones no contributivas en Argentina. Sobre el Ministerio de Desarrollo Social de la Nación (2000-2018)». Estudios Sociales del Estado, Vol. 5, n. ${ }^{o} 10$, p. 16-59.

- (2017). «El gobierno de la pobreza en la Argentina de la posconvertibilidad. El Ministerio de Desarrollo Social de la Nación». Buenos Aires, Fundación CECE.

Gasparini, L., Tornarolli, L. y Gluzmann, P. (2019). El desafío de la pobreza en Argentina. Diagnóstico y perspectivas. Buenos Aires: CEDLAS, CIPPEC, PNUD.

Guerra, P. (2012). Las legislaciones sobre economía social y solidaria en América Latina. Entre la autogestión y la visión sectorial. Revista de la Facultad de Derecho. 33(2), 73-94

Grassi, E. (2012). "Política sociolaboral en la Argentina. Alcances, novedades y salvedades». Revista de Ciencias Sociales, n. ${ }^{\circ}$ 135, pp. 185-198. 
Hintze, S. (2018) «Políticas, asociatividad y autogestión en la Argentina post $2015 \mathrm{El}$ punto de vista de los sujetos» en Revista Otra Economia, 11(20), pp. 136-155

- (2007). Políticas sociales argentinas 1990-2006. En Vuotto, Mirta (coord.) Las co-construcciones de las politicas públicas en el campo de la economía social. Buenos Aires, Prometeo Libros.

Hopp, M. (2018). De la promoción del trabajo cooperativo al Salario Social Complementario. Transformaciones en la transferencia de ingresos por trabajo en la Argentina. Ciudadanias. vista de Politicas Sociales Urbanas, 2, 113-42.

- (2017). Transformaciones en las políticas sociales de promoción de la economía social y del trabajo en la economía popular en la Argentina actual. Cartografias del Sur, 6, 19-41.

- (2013). ¿Cooperativas o planes sociales?: un análisis del proceso de implementación del Programa de Ingreso Social con Trabajo "Argentina Trabaja» en un municipio del Conurbano Bonaerense. En X Jornadas de Sociología. Facultad de Ciencias Sociales, Buenos Aires: Universidad de Buenos Aires.

- y Giménez S. (2011). Programa Ingreso Social con Trabajo Argentina Trabaja: una mirada reflexiva desde el corazón de su implementación. En IV Encuentro Internacional «Políticas Públicas y Trabajo Social. Aportes para la construcción de lo público», Buenos Aires.

- (2009). La construcción de sentidos del trabajo en las políticas de desarrollo socio-productivo en la Argentina post-convertibilidad. Margen. 55. 13-19.

Hudson, J. P. (2018) Políticas públicas de promoción de la autogestión cooperativa de la alianza Cambiemos, 2016 y 2017. Revista Perspectivas de Politicas Pública. 8(15). 173-205.

Maldovan Bonelli, J.; Ynoub, E.; Fernández Mouján, L. y Moler E. (2017). Políticas públicas e instituciones de regulación socio-laboral para la Economía Popular. upuestos y tensiones en el debate por la ley de Emergencia Social. En 13. ${ }^{\circ}$ Congreso Nacional de Estudios del Trabajo, Facultad de Ciencias Económicas de la Universidad de Buenos Aires.

Manzano V. (2013) La politica en movimiento. Movilizaciones colectivas y politicas estatales en la vida del Gran Buenos Aires. Prohistoria Ediciones: Rosario. Colección Biblioteca de Antropología. 362 pp.

Marañon, B. (2015) La economía solidaria en México / coordinador Boris Maranón Pimentel. - Primera edición. - UNAM, Instituto de Investigaciones Económicas. 222 páginas.

Marticorena, C. (2014) Trabajo y negociación colectiva. Los trabajadores de la industria argentina, de los noventa a la posconvertibilidad. Ed Imago Mundi; Buenos Aires.

Merino, G. (2019). Guerra comercial y América Latina (En línea). Revista de Relaciones Internacionales de la UNAM, (134): 67-98. Recuperado de: Http:// www.memoria.fahce.unlp.edu.ar/art_revistas/pr.10054/pr.10054.pdf

Modonessi, M. (2015). «Fin de la hegemonía progresista y giro regresivo en América Latina. Una contribución gramsciana al debate sobre el fin de ciclo». Viento Sur, No. 142, pp. 23-30. 
Moreira, C. (2017). El largo ciclo del progresismo latinoamericano y su freno: los cambios políticos en América Latina de la última década (2003-2015). Revista Brasileira de Ciências Sociais, 32(93). Disponible en: <http://www. scielo.br/scielo.php?script=sci_arttext\&pid=S0102-69092017000100301\&lng $=\mathrm{pt} \& \mathrm{nrm}=\mathrm{iso}>$.

Muñoz, M. (2019). Las marcas de los sujetos en el Estado. Los trabajadores de la economía popular y las políticas públicas en la Argentina reciente. Documentos y aportes en administración pública y gestión estatal, 18(30), 85-128.

Nadur, Y. (2019). Programa Ellas hacen: tensiones entre las exigencias y el fortalecimiento de la autonomía en mujeres / madres. (Tesis de Maestría). FLACSO. Sede Académica Argentina, Buenos Aires.

Oulhaj, L. (2016). Avanzar en la inclusión financiera. Propuestas en torno a la conceptualización y al marco legal desde dos cooperativas de ahorro y préstamo como actores de las finanzas solidarias en México. Ciudad de Mexico: Universidad Iberoamericana.

Palomino, H. (2004). Las experiencias actuales de autogestión en Argentina. Nueva Sociedad. 184, 115-128.

Pérez de Mendiguren J. P. y E. Etxezarreta (2015). Sobre el concepto de economía social y solidaria: aproximaciones desde Europa y América Latina. Revista de Economía Mundial. 40, 123-144

Piva, A. (2013) ¿Cuánto hay de nuevo y cuánto de populismo en el neopopulismo? Kirchnerismo y peronismo en la Argentina post 2001. Revista Trabajo y Sociedad. 21, 135-157.

Raggio, L. (2005). De las necesidades básicas a la construcción de autonomía. Una contribución desde la perspectiva antropológica al estudio de las politicas sociales. (Tesis de Maestría en Administración Pública). Facultad de Ciencias Económicas. UBA.

Rendon Corona, A. (2014). Crítica a la Ley de Economía Social y Solidaria y su reforma. Revista Rúbricas. 06, 45-53

Rodríguez, María Carla, y Vanesa Paola Ciolli (2011). Tensiones entre el emprendedorismo y la autogestión: el papel de las políticas públicas en este recorrido. Org \& Demo, Marilia. 12(1), 27-46.

Ruggeri, A. (2014). «Informe del IV relevamiento de Empresas Recuperadas en la Argentina. 2014: las empresas recuperadas en el período 2010-2013» (1. ${ }^{\mathrm{a}}$ ed.). Ciudad Autónoma de Buenos Aires: Cooperativa Chilavert Artes Gráficas, 2014.

Salvia A. (2010). «Heterogeneidad estructural y segmentación del mercado de trabajo en dos contextos económicos. Argentina 1998-2006» En VI Congreso de la Asociación Latinoamericana de Sociología del Trabajo. Ciudad de Mexico.

Vitali, S. Cavigliasso, C y L. Lilli (2019). «Debates y perspectivas en torno a la economía popular, social y solidaria: una aproximación a diferentes experiencias organizativas de la ciudad de Rosario». En XIV JORNADAS ROSARINAS DE ANTROPOLOGÍA SOCIO-CULTURAL «Antropología(s) en el contexto sociopolitico actual. Debates y desafios en clave Latinoamericana», Facultad de $\mathrm{Hu}-$ manidades y Artes-UNR. Rosario. 


\section{Fuentes}

Coneval (2019). «Ficha de monitoreo 2017-2018. Programa a Fomento de la economía social». México: Consejo Nacional de Evaluación de la Política Pública de Desarrollo Social.

Coneval (2019). «Ficha de monitoreo 2018-2019. Programa a Fomento de la economía social». México: Consejo Nacional de Evaluación de la Política Pública de Desarrollo Social.

Ley 20744 Título IV CAPITULO II Ley 20744.—Ley de Contrato de Trabajo, Del salario mínimo vital y móvil.-Ley General de la Economía Social y Solidaria. Disponible en: http://www.senado.gob.mx/index.php?ver=sp\&mn=3 \&sm=3\&lg=61\&ano=2\&id=27134 Cámara de Diputados, LXII Legislatura. Mintuta Proyecto de Decreto por el que se reforman diversas disposiciones de la Ley de Economía Social y Solidaria, reglamentaria del párrafo séptimo del artículo 25 de la Constitución Política de los Estados Unidos Mexicanos en lo referente al sector social de la economía. Mesa Directiva, 25 de abril de 2013, 14 pp. Congreso General.

Ley de la Economía Social y Solidaria. Publicación original DOF 23-05-2012 y la última reforma publicada el 24 de enero de 2013 Disponibles en: http://www. diputados.gob.mx/LeyesBiblio/ref/less.htm

Ministerio de Desarrollo Social de la Nación. Resolución n. ${ }^{\text {4 4697/2010. Sobre el }}$ Programa de Ingreso Social con Trabajo. Buenos Aires, 5/8/2010. 